\title{
El margen de apreciación en el derecho humano a la vida: Restricción de derechos y respuesta del Tribunal de Estrasburgo
}

\author{
The margin of appreciation in international human right to life: \\ Restriction of personal rights and response of the Strasbourg Court
}

\author{
María MARTín SÁNCHEZ ${ }^{1}$ \\ Universidad de Castilla-La Mancha \\ maria.martin@uclm.es
}

\begin{abstract}
Resumen: El derecho humano a la vida plantea serias dificultades. El conflicto entre el derecho a la vida, el derecho a la vida privada y la protección de la propia vida, no obtiene una clara respuesta de los tribunales de derechos. Resulta imprescindible un ejercicio de ponderación que justifique la proporcionalidad de la restricción de derechos del individuo, por parte de algunos Estados. El Tribunal de Estrasburgo, garante de los derechos en Europa, ante la complejidad de dar una respuesta unánime en un marco de diversidad y de falta de consenso, recurre al libre margen de apreciación nacional. Esta doctrina permite al Tribunal Europeo
\end{abstract}

1 Profesora Titular (A) de Derecho Constitucional de la Universidad de Castilla-La Mancha. Doctora en Derecho Constitucional, por la Universidad de Castilla-La Mancha, España, Especialista en Derecho Europeo, por la Universidad de Montesquieu-Bordeaux IV, Francia e Investigadora en la Universidad de Pisa, Italia (2014). Coordinadora del Doctorado en Derecho Constitucional Latinoamericano (en extinción); Comité académico del Máster Universitario de Derecho Constitucional; y Coordinadora de varias ediciones del Curso de Postgrado en Derecho Constitucional para Iberoamericanos de la Universidad de Castilla-La Mancha, España. Autora de cinco monografías y de numerosos capítulos en obras colectivas y artículos de investigación en revistas especializadas.

Artículo recibido el 11.01.2020 y aceptado para publicación el 18.08.2020. 
ofrecer una respuesta abierta que se acomode a las distintas realidades jurídicas en Europa, aunque marca ciertos límites infranqueables que salvaguardan el contenido esencial de los derechos humanos, frenando una restricción jurídica 'pro-vida' desproporcionada. Sin embargo, juega con la ambigüedad compaginando la priorización de los 'valores morales profundos' por encima del consenso europeo, con una reciente priorización del derecho de la mujer a interrumpir su embarazo conforme a la ley nacional sobre la objeción de conciencia de los sanitarios, lo que podría aventurar una tendencia pro-libertad (pro-aborto y, por extensión, pro-eutanasia) en su jurisprudencia.

Palabras clave: Vida, derecho a la vida, vida privada, margen de apreciación, Tribunal Europeo de Derechos Humanos.

Abstract: The human right to life poses serious difficulties. The conflict between the right to life, the right to privacy and the protection of life itself, does not obtain a clear answer from the courts of rights. A balancing exercise that justifies the proportionality of the restriction of the individual's rights by some States is essential. The Strasbourg Court, guarantor of rights in Europe, faced with the complexity of giving a unanimous answer in a framework of diversity and lack of consensus, resorts to the free margin of national appreciation. This doctrine allows the European Court to offer an open response that accommodates the different legal realities in Europe, although it marks certain insurmountable limits that safeguard the essential content of human rights, restraining a disproportionate 'pro-life' legal restriction. However, it plays on ambiguity by combining the prioritization of 'deep moral values' over the European consensus, with a recent prioritization of the right of women to terminate their pregnancy in accordance with national law on conscientious objection by health workers, which could risk a pro-freedom tendency (pro-abortion and, by extension, pro-euthanasia) in its jurisprudence.

Keywords: Life, right to life, private life, margin of appreciation, European Court of Human Rights. 


\section{Planteamiento introductorio: vida vs. libertad. Hipótesis de la cuestión y conflictos en juego.}

De entre todos, uno de los derechos sobre los que más se ha escrito es el derecho a la vida, si bien, probablemente también es uno sobre los que menos se ha podido concluir, dejando profundas cuestiones abiertas que a veces resultan cuasi-imposibles de ser resueltas por el Derecho.

El tándem vida y derecho a la vida resulta tan imposible como inseparable, más aún, cuando además de verse implicados otros derechos, el factor moral y ético incide de manera inexorable sobre ambos y conduce a soluciones absolutamente dispares.

El concepto vida es cosa distinta del derecho a vivirla, y cuando el Derecho interviene para garantizar plenamente el goce del derecho del individuo a «vivir» encuentra su límite justamente en su deber de protección de aquella como bien jurídico amparado constitucionalmente.

Algunas voces han sostenido la superioridad del derecho a la vida sobre el resto de los derechos, por entenderlo como el derecho preexistente y presupuesto necesario para la existencia de cualquier otro derecho de la persona. Sin embargo, no existen derechos «de primera» $\mathrm{y}$ «de segunda». Todos gozan de igual entidad y valor, y del mismo modo todos son susceptibles de ser limitados a partir de un ejercicio de ponderación, cuando entran en colisión con algún otro derecho o con otros valores superiores subyacentes como son la libertad, la igualdad, la dignidad y el libre desarrollo de la personalidad.

Ahora bien, si el examen de ponderación ya es complicado, en cualquier caso, mayor dificultad encuentra cuando uno de los derechos implicados es el derecho a la vida, máxime cuando la vida en sí misma es uno de los bienes protegidos en juego y que paradójicamente choca con aquél.

El derecho a la vida se proclama, como no podía ser de otro modo, en todas las cartas internacionales de derechos humanos. Así, la Declaración Universal de Derechos Humanos, de 10 de diciembre de 1948: «Todo individuo tiene derecho a la vida, a la libertad y a la seguridad de su persona» (artículo 3).

El Pacto Internacional de Derechos Civiles y Políticos, de 16 de diciembre de 1966: «El derecho a la vida es inherente a la persona humana. Este derecho estará protegido por la ley. Nadie podrá ser privado de la vida arbitrariamente» (artículo 6)

Siguiendo el modelo, también se ha proclamado en los Tratados de Derechos de ámbito regional más relevantes. Así reza la Convención Americana de Dere- 
chos Humanos de 1969, sobre el derecho a la vida: «1. Toda persona tiene derecho a que se respete su vida. Este derecho estará protegido por la ley y, en general, a partir del momento de la concepción. Nadie puede ser privado de la vida arbitrariamente».

Por su parte, el Convenio Europeo de Derechos Humanos, de 4 de noviembre de 1950, proclama el derecho a la vida del siguiente modo: «El derecho de toda persona a la vida está protegido por la ley. Nadie podrá ser privado de su vida intencionadamente $(. .$.$) ».$

En la Unión Europea, la Carta de los Derechos Fundamentales de la Unión Europea, de 12 de diciembre de 2007 (sustituye a la Carta proclamada el 7 de diciembre de 2000, desde la entrada en vigor del Tratado de Lisboa, el día 1 de diciembre de 2009), con un carácter más moderno, hace una previsión de mayor alcance. Así, más allá de reconocer el derecho a la integridad de la persona, introduce en su apartado segundo una cuestión de extraordinario alcance: «1. Toda persona tiene derecho a su integridad física y psíquica. 2. En el marco de la medicina y la biología se respetarán en particular: a) el consentimiento libre e informado de la persona de que se trate, de acuerdo con las modalidades establecidas por la ley; b) la prohibición de las prácticas eugenésicas, en particular las que tienen como finalidad la selección de las personas; c) la prohibición de que el cuerpo humano o partes del mismo en cuanto tales se conviertan en objeto de lucro; d) la prohibición de la clonación reproductora de seres humanos» (artículo 3)

De todos ellos se extrae una inequívoca conclusión: no definen el contenido del derecho a la vida. Ni siquiera una aproximación al mismo. Tan solo mencionan lo obvio, que todos tenemos derecho a vivir, algo en principio redundante al hecho de nacer y existir. Solo entran en la prohibición de la pena de muerte y de los tratos inhumanos y degradantes que, por otra parte, y sin ánimo de crítica, también resultan un tanto redundantes tras la proclamación de la integridad. Aunque con pequeños matices, sobre los que tendremos oportunidad de pronunciarnos más adelante, todos siguen el mismo modelo.

Se deduce una intencionada ausencia de precisión que abre un ilimitado abanico de posibilidades a constituyentes y legisladores. Posiblemente esta apertura es una de las razones de su imprecisión, pero seguramente obedece también al alcance moral, ético e incluso religioso que subyace en la definición del derecho a la vida y, lo que esto significa, la libertad de disponer sobre la propia vida. 
Que todos tenemos el derecho a vivir es un hecho incontestable desde el mismo momento en que existimos. Ahora bien, la imprecisión gira en torno a cuándo comienza dicha existencia y hasta cuándo debe protegerse la misma. ¿Puede desasociarse el derecho a vivir del comienzo de la propia vida?, ¿ es la persona libre de determinar el fin de su propia existencia?

La libre autonomía de la voluntad, el libre desarrollo de la personalidad, ¿justifican la libre disposición de la propia vida?, es más ¿podrían amparar la comercialización con la vida, incluso aunque se hiciera de forma altruista?, me refiero al caso de los vientres incubadora o a la maternidad subrogada.

Por su parte, el constante proceso de modernización y las increíbles posibilidades que nos ofrece la ciencia abren nuevas incógnitas: ¿cualquier técnica de reproducción debe considerarse legítima?, ¿estamos ante un nuevo derecho a la reproducción, a la maternidad?, ¿el avance de la ciencia avala la manipulación genética?, ¿dónde están los límites éticos en la investigación científica?

Aquí es donde entran en juego los tribunales de derechos humanos. Estos son los que, no solo guardan lo previsto en estas Cartas de derechos, sino que forjan a través de su jurisprudencia los auténticos contenidos de los enunciados previstos en ellas.

Así, la respuesta está en la interpretación que de los derechos humanos hagan dichos tribunales, muy especialmente respecto a derechos tan ambiguos e imprecisos como el derecho a la vida.

El presente trabajo pretende entrar en los conflictos más importantes en relación con la vida como valor superior y el derecho a la vida como derecho humano: su inicio y su final. Dos conceptos inseparables (vida y derecho a la vida) que a veces entran en conflicto. Lo anterior, a partir de la respuesta que ha dado el Tribunal Europeo de Derechos Humanos (TEDH en adelante) a través de su jurisprudencia. Una vaga respuesta hasta la fecha, que justifica en la 'inidoneidad' de adoptar una decisión unánime en el complejo y diverso contexto europeo, recurriendo al margen de libre apreciación nacional («vía de escape» ante los denominados conflictos «difíciles»)

Analizaremos la amplitud del margen de apreciación dado a los Estados en su determinación de la vida y sus límites, cuya delimitación se hace imprescindible para determinar la legitimidad de las restricciones impuestas sobre la libertad de las personas. 
A través del análisis de su jurisprudencia intentaremos dilucidar si en verdad existe un derecho a decidir sobre la vida, amparado en la libertad y en la vida privada y familiar, o si al contrario el Estado puede limitar nuestra libertad justificándose en valores superiores a nuestros propios derechos (como podrían ser los 'profundos valores morales')

El Convenio Europeo de Derechos Humanos (CEDH en adelante): ¿ampara el aborto, entendido como la libertad de las mujeres de decidir sobre su maternidad como extensión de su derecho a la vida privada y familiar, su integridad y su salud?, ¿ampara el derecho a morir, entendido como la libertad de las personas para decidir cómo quieren vivir el proceso final de su vida?, o al contrario ¿existen valores que justifican la restricción de la libertad de las personas por parte de los Estados? Estas restricciones ¿tienen cabida al abrigo de los derechos humanos?

Veremos cuál es la respuesta dada hasta ahora por el Tribunal de Estrasburgo y cuál se advierte como nueva tendencia para un futuro.

Partiremos de unas reflexiones iniciales sobre el derecho a la vida y su conexión con otros derechos y, a partir de ahí, entraremos en el análisis del aborto y después del pretendido derecho a morir, desde los parámetros jurisprudenciales dados para ponderar la libertad de decisión de los Estados y la de las personas.

\section{Evolución jurisprudencial del TEDH en la interpretación del derecho a la vida: restricción de derechos, margen de apreciación nacional y contradicciones}

Como apuntamos anteriormente, no es la letra del Convenio la que dota de contenido al derecho a la vida, sino lo que, sobre éste, han previsto los constituyentes y los legisladores y, por encima de éstos, lo que ha interpretado el Tribunal Europeo de Derechos Humanos.

En una región en la que conviven ordenamientos muy dispares, reflejo de contextos sociales y culturales muy alejados en los que muchas veces la tradición e incluso la religión juegan un elemento importantísimo - tal es el caso de Italia-, la labor interpretativa del Tribunal de Estrasburgo resulta a todas luces imprescindible.

A través de su jurisprudencia se ha conseguido a lo largo de los años, fomentar los principios democráticos y los valores constitucionales, incentivar el respecto a los derechos humanos, hacer partícipes a los propios individuos en la defensa de sus derechos, reconociéndolos como auténticos sujetos de derecho internacional 
capaces de acudir a una entidad supranacional, unificar doctrinas entre los distintos Tribunales Constitucionales o Cortes Supremas, en su caso, o incluso aunar algunos criterios en la interpretación del contenido de los derechos.

No obstante, el Tribunal Europeo de Derechos Humanos, muchas veces se ha limitado a constatar el conflicto de derechos, dejando en manos de los propios Estados la resolución de casos especialmente complejos -relacionados normalmente con conflictos de derechos de difícil resolución-, amparado en la doctrina del margen de libre apreciación nacional.

Otra de las cuestiones más relevantes en este contexto, es la eficacia de las sentencias dictadas por la Corte europea. Lejos de tener un alcance inmediato sobre las jurisdicciones de derechos de los Estados, y pese al compromiso de éstos de darles cumplimiento, su eficacia queda condicionada al grado de ejecutoriedad que cada Estado soberano decida darle, dependiendo en gran medida de los mecanismos de ejecución y de control previstos en cada ordenamiento jurídico.

En España, es la propia Constitución la que prevé expresamente la interpretación de los derechos a la luz de lo previsto en el Convenio: «Las normas relativas a los derechos fundamentales y a las libertades que la Constitución reconoce se interpretarán de conformidad con la Declaración Universal de Derechos Humanos y los tratados y acuerdos internacionales sobre las mismas materias ratificados por España» (artículo 10.2 Constitución española)

En consecuencia, no solo es la letra del Convenio Europeo la que condiciona la interpretación de los derechos constitucionalmente reconocidos, sino también la interpretación que de ellos realice el Tribunal Europeo de Derechos Humanos, como máxima instancia europea en la materia.

Sin embargo, la ausencia de mecanismos eficaces de control del cumplimiento de sus sentencias deja en manos de los Estados el efectivo cumplimiento de las mismas. Nótese la diferencia con el sistema americano de derechos, a tenor de la directa eficacia y cumplimiento interno de las sentencias dictadas por la Corte Interamericana de Derechos Humanos, que en ocasiones ha originado incluso la reforma constitucional de alguno de los Estados implicados.

Retomando el tema que nos ocupa, el derecho a la vida, es oportuno que como punto de partida dediquemos unos párrafos a delimitarlo, diferenciándolo de otros derechos que, aunque relacionados, no puede identificarse con aquél. $\mathrm{Me}$ refiero al derecho a la vida privada, proclamado en el artículo 8 del Convenio Europeo. 
La vida privada es un concepto de extraordinarias dimensiones, en el que tienen cabida numerosas manifestaciones del desarrollo personal y familiar, pero no el derecho a la vida. Ahora bien, en numerosas ocasiones aparecen vinculados en conflictos de derechos relacionados con la vida, en los que el respeto a la vida privada y familiar puede verse implicado como uno de los derechos en conflicto. Me refiero a supuestos en los que la mujer embarazada decide interrumpir su embarazo, entre otros, en defensa del pleno desarrollo de su vida privada y familiar; supuestos en los que la persona titular de derechos reclama su derecho a morir, desde la garantía de su vida privada; o incluso cuando se niega a someterse a determinados tratamientos médicos o intervenciones corporales, en defensa también de su vida privada.

En cualquiera de los casos, la vida privada y familiar interviene como garantía del margen de libertad y capacidad de decisión de su titular, frente a la intervención del Estado o de terceros que pretenden de algún modo, establecer restricciones sobre su propia vida privada a través de límites como la prohibición de abortar o de poner fin a su propia vida.

Junto al derecho a la vida, se proclaman otros derechos relacionados, pero autónomos e independientes de aquella. Se trata del derecho a la integridad y la prohibición de torturas y tratos inhumanos o degradantes. En efecto, conexos con la vida por cuanto su violación conlleva necesariamente un menoscabo de aquella, pero con entidad propia.

Dada la complejidad del derecho a la vida, no abordaremos en estas páginas el derecho a la integridad física de manera exhaustiva, pues se apartaría de nuestro objeto de estudio ${ }^{2}$. No obstante, dada la conexión entre ambos, se hará imprescindible hacer referencia a la integridad en cualquiera de los conflictos de derechos que plantearemos en torno a la vida en sentido estricto. Así, la integridad física y psíquica constituye uno de los derechos de la madre que decide abortar, como derecho de quien pretende acabar con su vida, o de quien se niega a determinadas intervenciones físicas.

La protección del derecho a la integridad previsto en las cartas de derechos se traduce además por los tribunales (amparándose en su dimensión física, psíquica y sexual), en la protección del individuo frente a prácticas como la esterilización (caso de incapacidad), o con el derecho a la identidad sexual, entre otros.

2 A este respecto, una perspectiva más amplia de la protección de la vida en relación con la integridad física, se recomienda: MOLERO (2014) 
Con todo, nuestro propósito en las páginas que siguen es abordar el derecho a la vida, desde los conflictos más importantes relacionados con ella y a la luz de la jurisprudencia del Tribunal Europeo de Derechos Humanos -alejándonos de la dimensión puramente teórica-.

Son infinitas las teorías vertidas sobre los conflictos relacionados con el derecho a la vida, hasta la fecha no resueltos ni por la doctrina ni por los tribunales de derechos, pese a los dispares intentos de los legisladores. La vida es probablemente la cuestión en la que más calado tienen las cuestiones éticas, morales e incluso religiosas, de modo que suman dificultad a la ya complicada resolución de los conflictos de derechos subjetivos implicados en torno a ella. De hecho, entre las disposiciones del Convenio consideradas primordiales, el Tribunal concede preeminencia al derecho a la vida ${ }^{3}$.

Los conflictos más relevantes se ubican en el inicio y el final de la vida -aborto y eutanasia, respectivamente-. Junto a los anteriores, otros conflictos relacionados con los métodos de reproducción artificial, la manipulación de embriones ${ }^{4}$, o incluso el pretendido derecho a la procreación -maternidad subrogada-, cuya aceptación también plantea dudas relacionadas con el derecho a la vida y la protección la vida como valor fundamental (en las que no entraremos)

\subsection{Libertad y vida privada vs. vida humana: ¿derecho al aborto?}

La vida humana no nace con la persona, sino antes, desde la mera existencia del ser humano. El Convenio Europeo de Derechos Humanos no hace mención a la misma; tampoco muchas constituciones nacionales (la Constitución española, por poner un ejemplo), obviando su consideración en el plano jurídico constitucional, imprescindible para determinar la protección constitucional del ser humano no nacido, portador de vida. Han sido los legisladores quienes han resuelto

\footnotetext{
3 Tribunal Europeo de Derechos Humanos, n.18984/91, 27 de septiembre de 1995, ap. 149-150: «El artículo 2 protege el derecho a la vida, sin el cual el goce de ninguno de los demás derechos y libertades garantizados por el Convenio sería ilusorio. Define las circunstancias limitadas en las que está permitido infligir intencionadamente la muerte, y el Tribunal ha aplicado un control estricto cada vez que dichas excepciones son invocadas por los gobiernos demandados»

4 En España, la tendencia legislativa y jurisprudencial es la 'gradualidad', así lo explica Gómez (2018), p.48: «(...) tanto el legislador como la doctrina del Tribunal Constitucional se han inclinado por una protección gradualista de la vida humana en formación que deja abiertos muchos interrogantes desde la perspectiva del derecho a la vida (art. $15 \mathrm{CE}$ ) y la dignidad humana (art. 10.1 CE)», tesis con la que coincido y que no resuelve de manera cierta algunas interrogantes respecto a la consideración del inicio de la vida.
} 
ésta y otras cuestiones, a través de la respuesta dada a la interrupción voluntaria del embarazo.

Ante esta laguna jurídica, los tribunales regionales de derechos aún no han dado una respuesta clara acerca de la ponderación aludida: la libertad de decisión de la mujer frente a la protección del no nacido, sino que se han limitado a establecer una serie de parámetros (abiertos a la interpretación) relacionados con la vida, el derecho a la vida y la capacidad de decisión de la mujer.

Trataremos de abordarlos a partir de las conclusiones extraídas de la jurisprudencia europea sobre la vida -que más adelante tendremos ocasión de analizar-: el «no nacido» no es persona, por lo que no es titular del derecho a la vida humana; el «no nacido» es portador de vida, entendida como valor constitucional digno de protección y recae sobre los poderes públicos el deber de protección del mismo, que será en última instancia de carácter penal; pero dicha protección puede ceder en determinados supuestos, cuando existe conflicto entre la vida de aquél y otros derechos.

Entrando en el fondo del asunto, comencemos por delimitar las principales cuestiones implicadas: primero, la consideración dada al no nacido (nasciturus); y consecuentemente, la ponderación entre éste y los derechos de la madre.

Ambas cuestiones han sido llevadas ante el Tribunal Europeo, aunque no ha dado respuesta a la cuestión de fondo, sino que ha centrado su jurisprudencia: bien en el margen de apreciación de los Estados para determinar si la prohibición del aborto es una restricción admisible en el marco del consenso europeo acerca de la vida; bien en el cumplimiento de la ley por parte de aquellos, en relación con la «dimensión procedimental del aborto»5.

De acuerdo con lo anterior, trataremos de extraer los aspectos más relevantes de su doctrina a través de un repaso jurisprudencial de sus pronunciamientos más relevantes sobre la protección de la vida en su inicio.

En relación con derecho de decisión de la madre, esto es, al pretendido derecho al aborto, el Tribunal ha tenido oportunidad de pronunciarse en diversas ocasiones, pero no ha querido dar respuesta a la cuestión. Sin embargo, llama poderosamente la atención que en sus últimos pronunciamientos se refiere al aborto para priorizarlo sobre el derecho legal a la objeción de conciencia de los sanitarios

5 Expresión acuñada por REY (2011). 
(concretamente de las comadronas), lo que podría aventurar un giro jurisprudencial hacia el reconocimiento del aborto como derecho. Veremos.

Haciendo un repaso de la jurisprudencia vertida respecto al aborto y el derecho a la vida, el Tribunal Europeo ha esquivado respuestas concretas y ha centrado sus pronunciamientos en cuestiones que podríamos resumir en: (1) la protección del nasciturus, (2) el margen de libre apreciación de los Estados en torno a la vida y al derecho a la vida privada, y (3) la ya mencionada dimensión procedimental del aborto (en relación a las obligaciones positivas de los Estados al respecto).

\subsubsection{Sobre la protección de la vida del nasciturus}

Comencemos por su doctrina sobre la consideración del «nasciturus». Este es el verdadero asunto de fondo, que resolvería cuantas incógnitas se platean en relación con la protección de la vida: la determinación o no del no nacido como persona, esto es, como titular de derechos ${ }^{6}$. Con esto, resultaría más fácil valorar la protección de éstos respecto a otros derechos implicados, a partir de un ejercicio de ponderación que resolvería la adecuación al Convenio, de la decisión de interrumpir voluntariamente un embarazo.

La previa delimitación jurídica del nasciturus, como persona titular de derechos, resultaba imprescindible para determinar si los tribunales deberían o no haber calificado la conducta de homicidio.

A través de su jurisprudencia, aunque sin resolver el tema de fondo, el Tribunal se ha pronunciado sobre otros aspectos ligados a él, y que sin duda alguna revelan importantes consideraciones acerca de su interpretación del artículo 2 del Convenio. Entre las pocas ocasiones en que el TEDH se ha pronunciado directamente sobre la concepción jurídica del nasciturus, encontramos dos pronunciamientos de partida.

Primero, la Decisión de la Comisión de 1980 (Asunto X. c. Reino Unido7), en la que ya se determinó que el nasciturus no se encuentra incluido en el término «persona» del artículo 2 del Convenio, de manera que no apreció vulneración del mismo por parte de las autoridades francesas que se negaron a considerarlo como

6 Entre sus férreos defensores, Alegre (2012), p.4: «(...) todo ser humano es titular de los derechos que la Constitución reconoce, lo cual se aprecia claramente en relación con el derecho a la vida: la lesión del mismo (quitar la vida a un ser humano) no sólo es irreversible, sino que obviamente le impide ejercer y disfrutar cualquier otro derecho: si no se respeta el derecho a la vida, da igual todo lo demás».

7 Decisión de la Comisión Europea de Derechos Humanos, n.7215/75, 13 de mayo de 1980. 
tal. En su razonamiento, no obstante, determinó que en todo caso son los Estados los competentes para determinar el comienzo de la vida, dentro de su libre margen de apreciación. En palabras del Tribunal: «(...) no es deseable, ni posible, responder en abstracto a la cuestión de si un no nacido es una persona a los efectos del artículo $2 \mathrm{CEDH»} \mathrm{(ap.} \mathrm{82).} \mathrm{Igual} \mathrm{haría} \mathrm{en} \mathrm{su} \mathrm{posterior} \mathrm{Asunto} \mathrm{Vo.} \mathrm{c.} \mathrm{Francia}{ }^{8}$. Este es un caso un tanto particular, pues no se demanda al Estado francés por prohibir el aborto, sino por practicarlo sin el consentimiento de la embarazada a causa de una negligencia médica. Se demandaba a los tribunales nacionales por no haber calificado la conducta del médico de «homicidio» intencional, por lo que la delimitación jurídica del nasciturus resultaba imprescindible para determinar si la conducta podía ser calificada como homicidio o no. Aplicando su propia doctrina, no apreció tampoco vulneración del artículo 2 por parte del Estado francés.

La protección jurídica del nasciturus resulta imprescindible para calificar penalmente las acciones contra él, así como para determinar el alcance de su protección constitucional. Y a partir de esta delimitación, concluir si la legalización del aborto podría ampararse o no.

Como punto de partida, se diferencian distintos niveles de protección más allá de la legalización o la prohibición absolutas: el aborto por supuestos o indicaciones, y el sistema de plazos. La diferenciación de ambos modelos es importante, no solo por la dimensión penal que pueden adquirir en los respectivos ordenamientos jurídicos internos, sino por la dimensión constitucional o de derechos.

En el modelo de supuestos, el aborto se concibe como excepción a la protección del no nacido, que en principio se prioriza sobre la decisión de la madre, solo permitida cuando el legislador así lo prevé. Lo anterior, a partir de un ejercicio de ponderación de los derechos y los bienes jurídicamente protegidos, que podrían amparar la decisión de la madre: su vida, su integridad física y psíquica, su derecho a la vida privada y familiar..., en definitiva, su capacidad de autodeterminación y su libertad de decisión.

El modelo de plazos invierte los términos. Se prioriza la decisión de la madre sobre la protección del no nacido, de manera que, dentro de los plazos previstos legalmente, éste queda absolutamente al amparo de lo que decida la madre. No haría falta recurrir a la ponderación, teniendo en cuenta además que el no nacido

8 Tribunal Europeo de Derechos Humanos, n.53924/oo, 8 de julio de 2004. 
no es titular de derechos que pudieran oponerse a los de la madre, dentro de los plazos estimados.

En los últimos años, ha habido un extraordinario cambio respecto a la protección jurídica del nasciturus y el consiguiente tratamiento jurídico dado al aborto. Se ha pasado de su concepción como delito, despenalizado en determinados supuestos, a la consideración del aborto como una decisión de la mujer en la que se ven implicados diversos derechos y bienes jurídicos que el legislador tiene que ponderar. En gran parte de Europa, la tendencia es la priorización de la decisión de la madre, pasando de la regulación de supuestos a la de plazos.

En la actualidad, se habla del aborto como «derecho» de la mujer. En efecto, se ven afectados derechos irrenunciables como la libertad sexual, la intimidad personal y familiar, la integridad psíquica, e incluso la libertad de convicciones, además de la integridad física, la salud e incluso la vida. El derecho a la salud, y el derecho a la atención sanitaria como parte de aquél, no son reconocidos como derechos autónomos por parte del Convenio Europeo de Derechos Humanos. Pero su estrecha conexión con derechos como la vida, la integridad física, psíquica y sexual, o la vida personal y familiar, entre otros, justifica su protección como tales. Dicho vínculo justifica que el TEDH haya dado a la salud y la atención sanitaria una protección muy cercana a la de aquellos9. De hecho, algunos autores defienden su consideración como auténticos derechos ${ }^{10}$.

Los Estados están comprometidos, en el marco de protección de los derechos humanos, a garantizar estos derechos sin mayores restricciones que las necesarias, razonables y proporcionadas. En cualquier caso, respetando el contenido esencial de la salud como auténtico derecho ${ }^{11}$. Pero aún no existe un reconocimiento como tal. Este reconocimiento marcaría una diferencia sustancial pues supondría su consideración del aborto como auténtico derecho garantizado por el Convenio, con alcance muy distinto a lo que hasta ahora es su mera permisión por parte del TEDH (cuando los Estados deciden legalizarlo)

En este sentido, se concibe el aborto como decisión de la mujer, con el único límite del plazo temporal marcado, y una vez se supera este primer plazo, mo-

9 Murillo de la Cueva (2019), p.7.

10 ReY (2018).

11 Monereo (2019), p.256: «(...) En dicho sistema garantista (...) se dota a este derecho de un auténtico «contenido esencial» resistente e intangible que pone límites a la discrecionalidad del legislador llamado a garantizar ese derecho respetando ese núcleo resistente o zona infranqueable». 
mento en el que el legislador fija la viabilidad fetal ${ }^{12}$, la decisión pasaría por una ponderación de los derechos de la mujer y la protección de la vida del no nacido. En definitiva, en la consideración jurídica del aborto caben dos opciones: bien dejarlo al arbitrio del Estado, o bien a la libertad de decisión de la madre. Veremos a continuación cuál es la respuesta del Tribunal europeo ante tal disyuntiva.

\subsubsection{El aborto como decisión de los Estados: la restricción de derechos y el consenso europeo en relación con el margen de apreciación \\ nacional}

El libre margen de apreciación nacional ha sido el paraguas del TEDH para pasar de puntillas sobre determinados conflictos de derechos, dejando en manos de los Estados la decisión al respecto. La soberanía justificaría así la 'no injerencia' del Tribunal europeo sobre las decisiones adoptadas por los tribunales nacionales. Normalmente esto ocurre en los conflictos de derechos más complejos de resolver, al verse implicadas cuestiones no jurídicas, de carácter ético, moral, religioso o cultural.

Es un concepto de extraordinaria relevancia, pues según como se entienda y según se dibujen los límites a la libertad de apreciación de los Estados para resol-

\footnotetext{
12 Como ejemplo, la vigente $\mathrm{LO}$ 2/2010, de 3 de marzo, de salud sexual y reproductiva y de la interrupción voluntaria del embarazo, concibe la interrupción del embarazo como libre decisión de la mujer dentro de un plazo (14 primeras semanas de gestación), a partir del cual se introducen una serie de supuestos en los que el plazo se extiende hasta las 22 semanas de gestación (en casos de grave riesgo para la vida o la salud de la embarazada y de riesgo de graves anomalías en el feto). ha supuesto un importante cambio respecto a la jurisprudencia -mantenida hasta la fecha- del Tribunal Constitucional, quien únicamente se ha pronunciado al respecto en su histórica STC de 11 de abril de 1985, caso despenalización del aborto. A pesar del cambio de criterio introducido a partir de la mencionada ley, esta sentencia sigue siendo el referente constitucional para resolver diversos interrogantes relacionados con la vida.

Algunos autores, a la espera de la decisión del Alto Tribunal español, esperan que éste resuelva 'en perspectiva de género', es decir, teniendo en cuenta los derechos sexuales y reproductivos de las mujeres por encima de otras consideraciones. Así GónZALEZ (2018), p.106: «(..) la vigente regulación se encuentra pendiente -van más de ocho años- de un recurso de inconstitucionalidad cuya resolución necesariamente tendrá que partir de la sentencia Tribunal Constitucional español 53/1985, que declaró adecuado al texto de 1978 el sistema de indicaciones, pero que, en ningún caso, podrá obviar el desarrollo y progresión de los derechos sexuales y reproductivos de la mujer, internacional y constitucionalmente reconocido»

En el mismo sentido: Ropero (2016), p. 240: «en el debate sobre el aborto parecen confluir las creencias sociales que han relegado en general los derechos de la mujer a un segundo plano, con aquellas que sitúan la maternidad en un ámbito sacralizado, que tiene que ver no sólo con determinadas convicciones religiosas $(\ldots) »$;
} 
ver sobre según qué derechos, estaríamos ante el riesgo de ver limitados derechos fundamentales bajo la aquiescencia del TEDH.

El tema que traemos entre manos, la vida, en relación con los derechos de carácter sexual y reproductivo de las mujeres, trae muy a propósito la cuestión del margen de apreciación nacional, sobre todo, respecto a uno de los grandes conflictos de derechos no resuelto, el derecho al aborto. Un derecho reivindicado a lo largo de la historia como símbolo libertad y de autodeterminación de las mujeres, relacionado no solo con la vida, sino con los derechos fundamentales a la vida privada y familiar, al libre desarrollo, a la integridad física, psíquica y sexual, y con otros que de manera tangencial pueden entrar también en juego (libertad de información y acceso a recursos judiciales efectivos)

El aborto, como cuestión ligada única y exclusivamente a las mujeres, en la que están en juego la libertad, la integridad e incluso la vida de las mujeres. Se trata de un conflicto de intereses que repercute única y exclusivamente sobre las mujeres. No se ven involucrados los derechos de los hombres, porque no hay un derecho a ser padre o a no serlo, no hay un derecho a la expectativa ni a la esperanza ${ }^{13}$.

En mi opinión, y así parece entenderlo el $\mathrm{TEDH}^{14}$, difícilmente podrían ser admitidas, pues no existe un derecho a la procreación, ni a la paternidad, y menos aún a la expectativa o la esperanza de ser padre, que pudiera ponderarse con la libertad de decisión de la madre ni con la protección al no nacido. Resulta oportuno mencionar aquí la reflexión hecha sobre este aspecto por el Tribunal Constitucional español, quien fue tajante al respecto, considerándola: «una situación que no tiene parangón con otra alguna, dada la especial relación del feto respecto de la madre, así como la confluencia de bienes y derechos constitucionales en juego $»^{15}$

El Tribunal europeo ha tenido numerosas ocasiones para pronunciarse acerca del aborto, para resolver conflictos de derechos provenientes de la aplicación de legislaciones más o menos restrictivas, con la intención de resolver si es o no una práctica amparable, a la luz del Convenio. La respuesta a esta interrogante no es

13 En este sentido se pronunció el TC español en su histórica sentencia n. 53/1985, de 11 de abril de 1985, sobre la ley del aborto.

14 A este respecto, recordamos la Decisión de la Comisión europea de Derechos Humanos,n.7215/25, de 13 de mayo de 1980, en la que se planteó una demanda en la que el recurrente, marido de una mujer en proceso de interrumpir voluntariamente su embarazo (y progenitor del no nacido en proceso), denunciaba la falta de reconocimiento de ningún derecho de los padres en la decisión de llevar a cabo un aborto, por parte del ordenamiento jurídico inglés. No obstante, la Comisión no se pronunció al respecto pues no era éste el objeto de su demanda, si bien la falta de atención sobre esta cuestión es, cuanto menos, reseñable.

15 Tribunal Constitucional español, n. 53/85, de 11 de abril de 1985, FJ.9. 
baladí, pues depende de ella que el aborto se confirme como derecho de la mujer, exigible en el marco del CEDH.

Es una cuestión de aquellas que presentan especial complejidad dadas las connotaciones morales, éticas y religiosas que entran en juego, en un marco de sociedades muy dispares en donde conviven las muy arraigadas a la tradición religiosa o cultural, con otras sin ningún tipo de arraigo.

Estos dos elementos han influido de forma determinante en la decisión el TEDH al respecto. De un lado, la connotación religiosa, moral o cultural de algunos países, a los que no puede imponérseles una solución contraria a la propia idiosincrasia de sus sociedades; y a su vez, una falta de consenso europeo que pudiera justificar la imposición de una respuesta unánime para todos.

Como también ha ocurrido en cuestiones igualmente complejas, el Tribunal ha optado por una respuesta salomónica, apelando al libre margen de apreciación de los Estados para determinar si el aborto es o no un derecho de la mujer. En este sentido, el Tribunal determina que no es un derecho extraíble del Convenio, pero que nada impide que los Estados soberanos, de acuerdo a sus contextos, lo reconozcan como tal ni que, al contrario, lo prohíban. Esta 'libertad' de decisión nacional tiene importantísimas repercusiones sobre las mujeres, lo que precisa determinar hasta dónde los Estados son libres para interferir en la libertad de la mujer, sin que se violen sus derechos.

Para conocer cómo actúa el TEDH en relación a la restricción de la libertad de las mujeres para decidir sobre su maternidad (así como de otros derechos implicados), lo haremos desde el examen del libre margen de apreciación nacional admitido por el mismo, advirtiendo dos etapas diferenciadas, a tenor su apreciación del aborto: desde la protección de la vida amparada en los valores morales profundos y la ausencia de amplio consenso europeo, o como cuestión inseparable del derecho a la vida privada y familiar (artículo 8).

2.1.2.1. Protección de la vida amparada en los valores morales profundos y en la ausencia de amplio consenso europeo.

El primer pronunciamiento de la Corte respecto al aborto lo encontramos en el Asunto Open Door c. Irlanda ${ }^{16}$. Se cuestionaba la condena del Estado irlandés a una asociación que asesoraba e informaba a las mujeres acerca de su posibilidad de salir a abortar al extranjero (actuación no prohibida por la ley irlandesa). En

16 Tribunal Europeo de Derechos Humanos, n.14234/88, 29 de octubre de 1992. 
este caso, el tribunal se aparta del examen de la libertad de las mujeres a decidir sobre su propio cuerpo, y orienta su pronunciamiento a la restricción de otros derechos y libertades vinculados con su capacidad de decidir: en este caso, el derecho a la libre información ${ }^{17}$. Tengamos en cuenta que, aunque su razonamiento se aleja del aborto en sí, la cuestión protagonista -la libertad de dar y recibir información- también forma parte de los derechos sexuales y reproductivos de las mujeres, en tanto derecho a ser informada y orientada sobre ésto ${ }^{18}$.

El Tribunal deriva la cuestión a los Estados y aprovecha para definir los parámetros en los que se mueve el margen de apreciación nacional (margen y límites en la libertad de decisión de los Estados), con la finalidad de conseguir un equilibrio en relación con los derechos de las mujeres. Aunque el pronunciamiento adolece de una falta de coherencia absoluta, desviando el centro de su análisis al artículo 10 (libertad de información, pues se juzgaba la condena impuesta a determinada asociación por facilitar información para la salida al extranjero con el fin de abortar) y no al derecho a la vida. Aunque esquiva pronunciarse respecto al aborto, resulta muy relevante entrar en su análisis para conocer los parámetros que maneja el Tribunal en relación con el margen de apreciación nacional (teniendo en cuenta además que tal información y orientación a las mujeres puede entenderse parte de sus derechos sexuales y reproductivos):

Sobre si las restricciones impuestas por el Estado violan el Convenio. El Tribunal confirmó que sobre los derechos no pueden establecerse restricciones por parte de las autoridades públicas más allá de las que: «(...) constituyan medidas necesarias, en una sociedad democrática, para la seguridad nacional, la integridad territorial o la seguridad pública, la defensa del orden y la prevención del delito, la protección de la salud o la moral, la protección de la reputación o de los derechos ajenos, para impedir la divulgación de informaciones confidenciales o para garantizar la autoridad y la imparcialidad del poder judicial». Todas ellas, excepciones que no concurrían en el caso, en opinión de la parte demandante, discutida por el Gobierno irlandés como parte demandada.

17 En relación con sus libertades de expresión, encontramos otros casos interesantes, a modo de ejemplo: Tribunal Europeo de Derechos Humanos, n.68416/o1, 10 de febrero de 2005.

18 Así lo h reconocido el Comité para la Eliminación de Todas las Formas de Discriminación contra la Mujer (CEDAW) entre otros, en su Dictamen Comunicación n.4/2004 c. Hungría, 14 de agosto de 2006. 
Sobre si la restricción de derechos estaba prevista legalmente (restricción a la libertad de información). El Tribunal observa que no existía previsión legal explícita y que tampoco era deducible de su regulación restrictiva del aborto.

Sobre la legitimidad de la restricción de derechos (respecto al artículo 10 $\mathrm{CEDH}$ ): legitimidad de sus fines, necesidad y proporcionalidad. Esta era la cuestión central para resolver, determinar si tal restricción podría considerarse legítima, esto es: la legitimidad de los fines perseguidos, la necesidad de la restricción en una sociedad democrática, y la proporcionalidad de tal medida.

En cuanto a la legitimidad de los fines perseguidos con la restricción, la parte demandada justificaba la legitimación de las restricciones en el objeto mismo de legislación irlandesa: protección de los derechos ajenos, la moral y la prevención del crimen. Ahora bien, ¿puede considerarse al nasciturus como titular de los «derechos ajenos» protegidos por la ley?; el gobierno irlandés entendía que sí, en contra de la posición de las demandantes.

El Tribunal inadmitió el argumento basado en la prevención del crimen, pero lejos de abordar el que a mi juicio era la clave para resolver el caso: la consideración o no del nasciturus como titular de derechos (derechos ajenos) centró su respuesta exclusivamente al argumento de protección de la moral. Así, avaló la legitimidad de las restricciones realizadas por la legislación irlandesa sobre la libertad de información a las mujeres con intención de abortar, en los valores morales de la sociedad irlandesa: «(...) la protección dada por el Derecho irlandés al derecho a la vida de los niños por nacer, reposa evidentemente en profundos valores morales relativos a la naturaleza de la vida; están traducidos en la actitud de la mayoría del pueblo irlandés que, en el referéndum de 1983, votó contra el aborto». Añade: «la restricción perseguía, por lo tanto, el fin legítimo de proteger la moral, uno de cuyos aspectos constituye en Irlanda la defensa del derecho a la vida del niño por nacer» (ap. 62)

Y cierra su argumentación apartándose intencionadamente del tema de fondo (el aborto): «A la vista de esta conclusión, no procede examinar si la palabra «ajeno» tal y como la emplea el artículo 10.2 engloba al niño por nacer», zanjando así una cuestión que, en realidad, era la que tendría que haber resuelto: la consideración o no del nasciturus como persona.

Entrando en el segundo de los parámetros exigidos al Estado para establecer medidas restrictivas de derechos (necesidad y proporcionalidad de la restricción en una sociedad democrática), éste resultó más complejo y difícil de justificar. 
El Tribunal determinó la 'inidoneidad' de dar una respuesta unánime vinculante para todos los Estados parte del Convenio acerca de cuestiones tan complejas como el derecho la vida, en las que hay fuertes connotaciones ideológicas, religiosas $y$ de orden moral, siendo inviable la imposición de una misma concepción moral en sus respectivos ordenamientos jurídicos. En palabras del Tribunal: «(...) se buscaría en vano en el orden jurídico y social de los Estados contratantes una noción europea uniforme de la moral». Advirtió que en esta cuestión: «(...) no se encuentra llamado, en este caso, a determinar si el Convenio garantiza un derecho al aborto o si el derecho a la vida, reconocido por el artículo 2, es igualmente válido para el feto» (ap. 66)

Dejaba así en manos de los Estados la responsabilidad de decidir acerca de la delimitación de la vida, por varias razones: primero porque ellos son quienes pueden dar mejor respuesta de acuerdo con sus respectivas realidades, y además, dada la falta de un amplio consenso europeo al respecto. Precisamente este es uno de los contenidos más relevantes del razonamiento del Tribunal, el margen de apreciación de los Estados en relación con la existencia o no de un amplio consenso europeo.

La ausencia de un fuerte consenso europeo respecto al derecho a la vida amplía aún más el margen de libre apreciación de los Estados, ante la falta de un criterio unánime. Cuando sí existe tal consenso, la decisión del Tribunal y consecuentemente la de los Estados, se ven condicionadas por aquél.

Por todo, pone en manos de los propios Estados la libertad para establecer restricciones de acuerdo con su ordenamiento jurídico, eso sí, sin que dicha libertad sea arbitraria, puesto que el límite impuesto por el Tribunal está en justificar la proporcionalidad de dichas medidas restrictivas, interpretando los derechos a la luz de su jurisprudencia.

A pesar de trazar los límites al margen de apreciación, obsérvese el alcance de sus palabras, de las que se deduce una conexión entre la libertad de los Estados para establecer restricciones y la moral, que años más tarde se acentuaría, tal y como tendremos oportunidad de abordar.

En el caso en cuestión, pese al margen de apreciación, condena a Irlanda, pero no porque no le reconozca la capacidad para establecer la restricción denunciada -que estaría justificada en las fuertes convicciones morales-, sino porque la restricción irlandesa era de carácter absoluto: «(...) la injerencia se revela demasiado amplia y desproporcionada» (ap. 74). Podríamos por lo tanto deducir que, de no 
haberse pronunciado en términos absolutos el tribunal irlandés, el Tribunal Europeo habría avalado la restricción.

A partir de la anterior, se suceden diversas demandas ante la Corte de Estrasburgo que van a ir construyendo la doctrina europea acerca del pretendido derecho al aborto. Primero, como en el Asunto Vo. c. Francia ${ }^{19}$, esquivó de nuevo pronunciarse respecto al derecho al aborto, amparado en el margen de apreciación nacional, y en la falta de consenso europeo al respecto.

\subsubsection{Conexión del aborto con el derecho a la vida privada (artículo 8 CEDH)}

Transcurridos algunos años, llegó un pronunciamiento de especial trascendencia, el Asunto $A B$ y C c. Irland $a^{20}$, en el que condenó a Irlanda por violación del artículo $8 \mathrm{CEDH}$. A pesar de que como decíamos, no entra en el examen del aborto como derecho, probablemente sea su sentencia más relevante en relación con la libertad reproductiva de las mujeres, y supone además un punto de inflexión en relación al margen de apreciación de los Estados, en conexión con las convicciones morales profundas.

En este caso, se plantea la contrariedad de la regulación irlandesa del aborto con el Convenio de Roma, presentándose como uno de los ordenamientos jurídicos más restrictivos en Europa, al permitir el aborto únicamente en casos de grave peligro de la vida de la madre que no pudiera evitarse salvo con la interrupción del embarazo.

Sin entrar en otras consideraciones (que en mi opinión se alejan del tema que nos ocupa), este asunto sirvió para que el TEDH se pronunciara sobre una cuestión determinante: la relación de la libertad reproductiva de las mujeres con su derecho a la vida privada y familiar (del artículo $8 \mathrm{CEDH}$ )

El Tribunal por primera vez estimó que la prohibición de abortar supone una injerencia en la vida privada y familiar, y en el desarrollo personal de las demandantes. Explica el Tribunal que, para justificar esta injerencia, tendrían que concurrir los requisitos antes dichos: que la injerencia estuviera prevista en la ley, respondiera a un objetivo legítimo y que además fuera necesaria en una sociedad democrática y proporcionada al objetivo perseguido.

19 Tribunal Europeo de Derechos Humanos, n.53924/oo, 8 de julio de 2004.

20 Tribunal Europeo de Derechos humanos, n.25579/05, 16 de diciembre de 2010. 
Tal y como ha explicado reiteradamente el Tribunal: «El artículo 8 tiene esencialmente por objeto proteger al individuo contra las injerencias arbitrarias de los poderes públicos. Toda injerencia en el derecho que enuncia el apartado 1 del artículo 8 debe estar justificada en virtud del apartado 2, es decir, deberá estar prevista por la ley y ser necesaria en una sociedad democrática para alcanzar uno o más de los fines legítimos citados. Según la constante jurisprudencia del Tribunal, la noción de necesidad implica una injerencia fundada en una necesidad social imperiosa y proporcional al fin legítimo perseguido por las autoridades $»^{21}$

En el caso, concurren con claridad los dos primeros requisitos (prohibición legal del aborto, con el objetivo de protección de los valores morales profundos de la sociedad irlandesa), ahora bien, más controversia existe en torno a la concurrencia o no del tercero de los requisitos. Como ocurre normalmente, cuando nos encontramos ante restricciones de derechos, el elemento más difícil de determinar es la necesidad y proporcionalidad, pues éstos responden más a juicios de valor que a elementos puramente objetivos. Para su resolución el TEDH recurre a la existencia o no de un amplio consenso europeo.

Tengamos en cuenta que, para contrastar la concurrencia de un amplio consenso europeo, basta con comprobar la posición convergente de la mayoría de los Estados en lo que el Tribunal ha denominado «interpretación evolutiva del Convenio $»^{22}$. Cuestión que pone en entredicho la autoridad del TEDH y que resta valor a su posición de máximo garante de derechos en Europa ${ }^{23}$.

Dada la carga moral y ética que subyace en este asunto, los Estados (en este caso Irlanda) disponen de un elevado margen de apreciación, que solo se vería reducido si existiera consenso europeo al respecto.

En Europa, la tendencia contrastada es favorable a la autorización del aborto, sin embargo, y en contradicción con su propia jurisprudencia mantenida hasta entonces, afirmó que el consenso en el grado de aceptación del aborto no justifica una reducción considerable del libre margen de apreciación nacional.

21 Tribunal Europeo de Derechos Humanos, n.5410/03, 20 de marzo de 2007, ap. 109.

22 Véase Tribunal Europeo de Derechos Humanos, n.71503/o1, 28 de noviembre de 1984, o Tribunal Europeo de Derechos Humanos, n.28957/95, 11 de julio de 2002.

23 Como explica Laura Clérigo en tono crítico, el TEDH de sirve de la falta de consenso para avalar restricciones de derechos: «(...) si identifica una ausencia de consenso regional, opta por el estancamiento hasta que 'soplen nuevos vientos'. Reconoce al Estado un amplio margen de apreciación y controla en forma leve las razones estatales dadas para la restricción de esos derechos» (p.60). Clérigo (2020), p.6o. 
Aquí está lo que a mi juicio es el contenido de mayor alcance de la sentencia. Siguiendo lo que habría sigo una continuidad en su línea jurisprudencial, un amplio consenso en la priorización de la vida privada de la madre ${ }^{24}$, derivado de la existencia de leyes que permiten el aborto en la mayoría de los Estados, habría justificado una reducción en el margen de apreciación que, de ninguna manera se habría evitado por razones como la existencia de valores o convicciones morales. Pero no lo hizo.

Esto, como antes se avanzó, supuso un peligrosísimo punto de inflexión en la doctrina del margen de apreciación de los Estados, al otorgar primacía a los valores morales profundos sobre el consenso europeo y sobre los derechos del Convenio.

Además, para justificase, el Tribunal manipuló el objeto de su examen. Se alejó de lo que en realidad era el tema de fondo: la restricción de la vida privada de la madre (artículo 8), sobre la que existe una reconocida tendencia a su protección -consenso europeo- (derivando su objeto de examen a la consideración del comienzo de la vida, sobre el que no existe consenso ${ }^{25}$ ). Reduce su juicio a la ponderación entre el derecho de autodeterminación de la madre y la protección del nasciturus como bien jurídico protegido.

Subyace además un error de fondo, pues no pueden ponderarse los derechos de la mujer con lo que no es un derecho (sino un valor jurídicamente protegido). En realidad, estaríamos ante un juicio de proporcionalidad de la restricción de derechos respecto a la protección del valor vida, influida por consideraciones morales.

Esta sentencia supuso un indudable menoscabo en la protección de los derechos del Convenio y de su función armonizadora en Europa, abriendo la puerta al riesgo de restricciones desproporcionadas de derechos, impuestas por voluntad de los Estados. La doctrina vertida en esta sentencia sería perfectamente extrapolable a otros conflictos relacionados con el derecho a la vida privada, como es el caso de: la prohibición de la eutanasia ${ }^{26}$ o de la prohibición de técnicas de reproducción asistida heterólogas ${ }^{27}$, la prohibición de matrimonio homosexual ${ }^{28}$,

24 Por encima de la consideración del no nacido.

25 Tribunal Europeo de Derechos Humanos, n.53924/oo, 8 de julio de 2004.

26 Tribunal Europeo de Derechos Humanos, n.2346/o2, 29 de abril de 2002.

27 Tribunal Europeo de Derechos Humanos, n.57813/oo, 3 de noviembre de 2011.

28 Tribunal Europeo de Derechos Humanos, n.30141/04, 24 de junio de 2010. 
y a otros conflictos como los relacionados con la libertad religiosa ${ }^{29}$, en los que también concurre una fuerte carga moral y ética.

Supuso un retroceso en el reconocimiento de la libertad y la vida privada de las mujeres, priorizando la protección del no nacido sobre los derechos de aquellas, y justificado la proporcionalidad de tal intromisión en base a los valores morales profundos (obviando el amplísimo consenso europeo sobre la vida privada y familiar, inseparable de la libertad de decidir de la mujer)

Los casos expuestos, reflejan la dificultad de someterse a un aborto en países con legislaciones restrictivas, a pesar de tener reconocida su legalidad en determinados supuestos.

La conclusión extraída del recorrido jurisprudencial, y a pesar de la vaguedad de sus argumentos y de la falta de contundencia en sus decisiones, es que el aborto no es un derecho fundamental extraído del Convenio, ni como derecho ubicado en el artículo 3 (derecho a la vida) ni como manifestación del artículo 8 (vida privada), a pesar del inseparable vínculo con ellos, admitido por el Tribunal.

La tendencia actual es la legalidad del aborto, regulado normalmente en leyes de plazos que no de supuestos, pero a pesar de esta tendencia cada vez más mayoritaria, el Tribunal opta por la ambigüedad, y prioriza la libertad de los Estados sobre la libertad de las mujeres. El margen de apreciación nacional, muy recurrido por los tribunales de derechos humanos (en particular, la Corte Interamericana de Derechos Humanos ${ }^{30}$ ), tampoco puede traducirse en la absoluta libertad por parte de aquellos ${ }^{31}$. Debe ajustarse a ciertos parámetros y límites que no pueden ser traspasados: previsión legal de la injerencia o restricción respecto a los compromisos asumidos internacionalmente en los convenios regionales de derechos humanos, que la restricción sea necesaria en una sociedad democrática para conseguir un fin legítimo, y proporcionalidad ${ }^{32}$. De ninguna manera el margen de apreciación nacional podría conllevar la reducción del contenido esencial de los derechos recogidos en el Convenio, siendo este el límite infranqueable en

29 Tribunal Europeo de Derechos Humanos, n.44774/98, 10 de noviembre de 2005.

30 Resultan interesantes para abordar esta cuestión en profundidad: PASCUAL (2013); Benavides (2009); López (2017); SÁNCHEZ-Molina (2016).

31 Algunos autores, como Javier García Roca, se han mostrado muy críticos con esta sobrevaloración del margen de apreciación nacional, refiriéndose a la soberanía de los Estados como: «un aparente obstáculo para admitir una revisión jurisdiccional plena». GARCía (2017), p. 118.

32 Freixes (1997). 
su actuación (el 'contralímite'). Por eso, en tanto el aborto (como otros ${ }^{33}$ ) no se reconozca como derecho extraíble del Convenio, su prohibición no supone violación al mismo.

Pero, de forma inesperada, en una reciente Decisión del Tribunal Europeo (Asuntos Grimmark y Steen c. Suecia ${ }^{34}$ ) se aventura un paso al frente por parte del Tribunal, al estimar que la objeción de conciencia de las comadronas (habrá que ver si es extensible o no a toda la profesión médica), no puede prevalecer sobre el derecho de las mujeres a interrumpir su embarazo. Por primera vez, el Tribunal se pronuncia respecto al aborto como extensión de los derechos de las mujeres en los siguientes términos: «(...) el objetivo legítimo de proteger la salud de las mujeres que quieran abortar». Estas decisiones son verdaderamente un punto y aparte en la jurisprudencia europea sobre el aborto.

$¿$ Es el aborto un derecho irrenunciable de las mujeres?

El TEDH, en este tema, no ha interpretado el Convenio en perspectiva de género. De hacerlo, habría tenido en cuenta que la situación real de algunas mujeres puede requerir adoptar ciertas decisiones relacionadas con su maternidad, que en realidad es una prolongación de su libertad, su desarrollo personal y familiar, y su derecho fundamental a la vida privada y familiar sin injerencias. De hecho, las constituciones nacionales no están pensadas en perspectiva de género, lo que complica el reconocimiento de los derechos sexuales y reproductivos de las mujeres ${ }^{35}$.

33 Otro claro ejemplo es el matrimonio homosexual, respecto al que no obliga a los estados a legalizarlos, pero tampoco les prohíbe hacerlo, tal y como afirmó por primera vez en: Tribunal Europeo de Derechos Humanos, 24 de junio de 2010 y, más recientemente, Tribunal Europeo de Derechos Humanos, 9 de junio de 2016.

34 Decisión del Tribunal Europeo de Derechos Humanos, 12 de marzo de 2020.

35 Levín (2018), pp.381-382: «La disputa feminista no es por una libertad en sentido abstracto, sino concreto, relacionada con los derechos inherentes a la condición de persona que, desde hace siglos, impide a las mujeres ser propietarias de sí mismas. Se fundamenta en los derechos personalísimos al entender que tanto la sexualidad como la reproducción son sustratos de la persona, que corresponden jurídicamente a la esfera de los derechos subjetivos y otorgan poder individual a aquellas decisiones que se ubican en estos planos. Este registro jurídico impone al poder público deberes de «no hacer» para no afectar las libertades. Se propone fundar una ciudadanía plena en la que la libertad del cuerpo de las mujeres sea una conquista de identidad política. Dicha conquista se sustenta, a su vez, en razones de justicia política, entendida como la necesidad de contar con una igualdad de libertades en la comunidad política. Esa igualdad supone también contar con la misma cantidad de libertad para todas las personas».

SALINERo (2018), p.19: «la salud sexual y reproductiva de la mujer ya era reconocida como parte del contenido del «Derecho a la Salud» que entraña una serie de derechos y de libertades, entre los que «figura el derecho a controlar su salud y su cuerpo con inclusión de la libertad sexual y genésica», abarcando, de manera específica, a la salud sexual y reproductiva como «factores determinantes», entre otros, de la salud de la mujer». 
Un examen en perspectiva de género supondría reconocer que el derecho a la vida, a la salud y a la vida privada de las mujeres, incluye necesariamente su libertad para decidir sobre su propio cuerpo. La resolución de este tipo de conflictos y la interpretación que se haga del Convenio no tiene repercusiones para los hombres, sino única y exclusivamente para las mujeres, dado su impacto real sobre ellas.

La plenitud de los derechos de las mujeres pasa por su interpretación en perspectiva de género. Lo contrario sería desatender la realidad de las mujeres, diferentes de los hombres.

\subsubsection{El aborto legal como derecho irrenunciable por parte de los Estados en su dimensión procedimental: ¿hacia su reconocimiento como derecho?}

El TEDH se ha pronunciado sobre otro importante aspecto relacionado con el derecho al aborto de las mujeres, en su dimensión procedimental. Esto es, sobre el cumplimiento de la ley por parte de los Estados, en lo que se refiere al respeto de la decisión de abortar de la mujer, en aquellos supuestos en los que la ley lo permite. Las autoridades públicas, ¿podrían incumplir la ley obstaculizando la práctica del aborto permitido legalmente, por cuestiones éticas o morales? La respuesta es no, y así se deduce de sus pronunciamientos.

En primer término, citemos el Asunto Tysiac c. Polonia ${ }^{36}$, cuya doctrina ha sido reiterada en posteriores pronunciamientos por el Tribunal Europeo. Se trata del caso de una mujer que, tras ser advertida del riesgo para su salud que suponía el embarazo, no tuvo acceso a pruebas de diagnóstico que confirmaran que concurrían las condiciones requeridas legalmente para la práctica de un aborto terapéutico, negándole así esta posibilidad.

\footnotetext{
En este sentido, algunos autores defienden el abandono del punitivismo en materia de interrupción del embarazo a partir del reconocimiento de la autonomía sexual: GónZALEz (2020).

Algunos autores incluso apuestan por la constitucionalización de los derechos sexuales y reproductivos de las mujeres, como Valenzuela y Villavicencio (2015), p.291: "cuando se aprueba una norma que criminaliza el aborto y/o cuando se reproduce esta norma en la jurisprudencia constitucional, confirmándola y sosteniendo que ella no vulnera la igualdad y la dignidad de las mujeres, quienes están legislando o llevando a cabo la judicatura, están vulnerando el referido imperativo categórico por cuanto están utilizando las capacidades reproductivas de las mujeres, en ausencia de sus voluntades, como un medio para perpetuar estereotipos de género que los benefician».

36 Tribunal Europeo de Derechos Humanos, n.5410/o3, 20 de marzo de 2007.
} 
En opinión del Tribunal: «el artículo 8 (...) puede crear también unas obligaciones positivas inherentes a un respeto efectivo de la vida privada. Estas obligaciones implican la adopción de medidas tendentes a asegurar el respeto de la vida privada hasta en las relaciones entre las personas, incluida tanto la creación de un marco reglamentario que instaure un mecanismo judicial y ejecutorio destinado a proteger los derechos de las personas como el establecimiento, allá donde proceda, de unas medidas específicas» (ap. 110)

$Y$ añade: «(...) ciertamente el artículo 8 no contiene ninguna exigencia procesal explícita, pero es importante, para el goce efectivo de los derechos garantizados por esta disposición, que el procedimiento decisorio sea equitativo y permita respetar como es debido los intereses que en él se salvaguardan. Procede determinar, habida cuenta de las circunstancias concretas de la causa, y en particular, de la naturaleza de las decisiones a adoptar, si la persona tuvo en el proceso decisorio, considerado en su conjunto, un papel suficientemente importante para asegurarle la protección exigida de sus intereses» (ap. 113)

Así, se condena a Polonia, no prohibir el aborto - fuera de discusión al no estar reconocido como derecho extraíble del Convenio-, sino por violar la previsión legal del mismo en su dimensión procedimental, por razones ideológicas y morales de los profesionales médicos.

En la línea de la anterior, nos referimos de nuevo al citado Asunto $A B$ y $C$ c. Irlanda ${ }^{37}$, en el que tuvo la ocasión de resolver separadamente la demanda presentada por tres demandantes en situaciones distintas, condenando a Irlanda por cuestiones procedimentales en una de ellas (enferma de cáncer cuyo embarazo pondría en grave riesgo su salud). Recordemos que, en este caso, la condena viene dada por la falta de medios previstos por el Estado para facilitar la salida de la demandante al extranjero a practicarse un aborto, concurriendo la circunstancia de grave riesgo para su salud, a pesar de que la ley irlandesa permitía dicha posibilidad.

Siguiendo idéntico criterio condenó a Polonia en sus Asunto R.R. c. Polonia ${ }^{38}$, y Asunto P y S c. Polonia ${ }^{39}$.

En la primera de ellas se resuelve acerca de la violación de los derechos de una mujer, a la que se le niega la práctica de una prueba médica que confirmaría la

37 Tribunal Europeo de Derechos Humanos, n.25579/05, 16 de diciembre de 2010.

38 Tribunal Europeo de Derechos Humanos, n.27617/04, 26 de mayo de 2011.

39 Tribunal Europeo de Derechos Humanos, n.57375/o8, 30 de octubre de 2012. 
presencia de graves malformaciones en el feto, y consecuentemente, se impide la interrupción de su embarazo. Tal y como explica el Tribunal, si bien el objeto esencial del artículo 8 es proteger al individuo frente a interferencias arbitrarias de las autoridades públicas, también puede imponer a los Estados ciertas obligaciones positivas para asegurar el respeto de los derechos protegidos en el mismo. En la última de ellas, el Tribunal condenó a Polonia por vulnerar los derechos de una mujer de 14 años, víctima de una violación, a quien se le dificultó la práctica de un aborto, permitido legalmente en dicho supuesto. Concurriendo además fuertes presiones sobre la menor por parte de las autoridades para evitar que interrumpiera su embarazo, poniéndola en una situación de tensión insoportable (dada su vulnerabilidad).

En ambos pronunciamientos, el Tribunal da un paso adelante y condena al Estado polaco no solo por violación del derecho a la vida privada y familiar de las demandantes, sino que incluso estima la concurrencia de un trato degradante por parte de aquél, proscrito en el artículo 3 del Convenio -prohibición de tratos inhumanos y degradantes-.

Los casos expuestos, reflejan la dificultad de someterse a un aborto en países con legislaciones restrictivas, a pesar de tener reconocida su legalidad en determinados supuestos. El Tribunal europeo no puede interferir en lo sustantivo (decisión de los Estados) pero sí en lo procedimental, en cuanto a que éstos garanticen los derechos reconocidos legalmente a las mujeres, sin que quepa su incumplimiento por cuestiones morales o religiosas.

Completando lo anterior, existe otro complejo asunto derivado directamente de la determinación del inicio de la vida y su consecuente protección constitucional: solo los pre-embriones viables son nasciturus. Si bien se trata de conceptos científicos, estas precisiones no dejan de influir en el plano jurídico. Si la protección se extendiera hasta la mera concepción, se plantearían otros conflictos relacionados por ejemplo con la píldora del día después (en relación con la objeción de conciencia ${ }^{40}$ frente a la dispensa de algunos medicamentos), o con la manipu-

40 En relación a la libertad de los médicos, el Tribunal Constitucional español, a modo de referencia, reconoció su derecho de objeción de conciencia: «(...) los profesionales sanitarios directamente implicados en la interrupción voluntaria del embarazo tendrán el derecho de ejercer la objeción de conciencia sin que el acceso y la calidad asistencial de la prestación puedan resultar menoscabadas por el ejercicio de la objeción de conciencia» (Tribunal Constitucional español, n. 53/85, 11 de abril de 1985, y así previsto en la actual legislación sobre el aborto en España, art. 19.2). 
lación de embriones, cuestión especialmente compleja en la que entraríamos en el campo de la bioética (que excede de nuestro objeto de estudio)

Con todo, de la jurisprudencia de Estrasburgo, extraemos las siguientes conclusiones:

(1) El aborto no es un derecho fundamental extraído del Convenio, por lo que a priori no puede prevalecer sobre la protección de la vida humana del no nacido, ni como derecho ubicado en el artículo 3 (derecho a la vida) ni como manifestación del artículo 8 (vida privada).

(2) El nasciturus no es titular de derechos, por lo que no pueden establecerse prohibiciones desproporcionadas al aborto por parte de los legisladores, a la luz de los derechos de la mujer, implicados en el mismo: integridad física y psíquica, y derecho a la vida privada y familiar.

(3) No puede limitarse la práctica de abortos permitidos legalmente, interponiendo obstáculos o no facilitando los medios adecuados, dificultando o incluso haciendo inviable su práctica.

Los valores morales profundos podrían justificar la prohibición del aborto, con sus consecuentes restricciones sobre otros derechos, pero no justificarían en ningún caso el incumplimiento de sus obligaciones por parte de las autoridades públicas (conforme a la ley)

\subsection{Delimitación de la libertad de disposición sobre la propia vida: ¿derecho a morir?}

El otro gran conflicto relacionado con el derecho a la vida gira en torno al final de la misma. La libertad de disposición de la vida plantea dos supuestos bien diferenciados. De un lado, el derecho a morir como dimensión negativa al derecho a la vida (eutanasia o muerte digna); y como cosa distinta, el rechazo a tratamientos médicos en ejercicio de su libertad y del derecho a la integridad física y moral (eutanasia pasiva). No entraremos en estos últimos, pues se alejan de lo que es estrictamente el derecho a la vida, aunque sus consecuencias pueden producir un menoscabo o incluso el fin de ésta.

Adviértase que cuando nos referimos a eutanasia pasiva, no estamos ante supuestos de mero rechazo a tratamientos forzosos: amparados en el derecho a la integridad física, psíquica o incluso sexual, pero en el que no se da el elemento objetivo de la incurabilidad y la absoluta falta de esperanza de vida (y en el que normalmente subyace también un ejercicio de la libertad ideológica o religiosa). 
La eutanasia no es cualquier forma de muerte deseada por el sujeto, sino sólo aquella que tiene como finalidad poner fin a la vida ante enfermedades incurables para evitar el sufrimiento. En esto se ve directamente implicada la «dignidad», a la que se apela como fundamento que justificaría dicha actuación. Sin embargo, hay que diferenciar la eutanasia activa (como acción encaminada a causar deliberadamente la muerte) de la eutanasia pasiva (como inactividad, esto es, no proporcionar tratamientos médicos que sólo alargan la vida del sujeto prolongando su agonía, pero sin posibilidad de curación).

El Tribunal europeo ha tenido ocasión de pronunciarse en diversas ocasiones respecto a lo que ha denominado "derecho a la muerte digna», esto es, vivir con dignidad el proceso final de la vida.

Tal y como ocurría en el caso de la determinación del inicio de la vida, en la que recurre al margen de apreciación nacional, en el caso de la determinación del proceso final de la vida emplea la misma técnica. En ambos casos, la única respuesta clara es que ni existe un derecho al aborto ni tampoco un derecho a decidir sobre el final de la vida, extraídos del Convenio. Si bien no prohíbe que cualquiera de los Estados parte del mismo puedan reconocerlo como tal, al amparo de su propio ordenamiento jurídico interno.

A continuación, haremos un repaso de su jurisprudencia para tratar de dilucidar algunas de las cuestiones más complejas y trataremos de extraer las conclusiones de la interpretación que el Tribunal ha hecho acerca del derecho a la muerte digna.

Para ello, hemos seleccionado las cinco sentencias más relevantes, por cuanto plantean diferentes supuestos complejos en relación con el pretendido derecho a morir, sobre los que el Tribunal ha tenido que pronunciarse. Así, se plantean, respectivamente: el pretendido reconocimiento del derecho a la muerte digna como parte del propio derecho a la vida ante situaciones de enfermedad incurable, la colaboración del Estado con el auxilio al suicidio en países en los que es legal, el auxilio al suicidio por vejez en ausencia de enfermedad incurable, la suspensión de la prolongación artificial de la vida por parte de las autoridades, o el polémico y más reciente caso de la asistencia al suicidio de un menor.

Trataremos de entrar en las consideraciones más relevantes de derechos en cada uno de los citados supuestos que ha resuelto el Tribunal al hilo de las sentencias que vamos a comentar. De todas ellas, haremos especial hincapié, como no podría ser de otro modo, en el memorable Asunto Pretty c. Reino Unido, por cuan- 
to contiene las consideraciones más importantes realizadas hasta la fecha acerca del pretendido derecho a la muerte digna, y sirve de base para el entendimiento de todas las posteriores.

\subsubsection{Derecho a la muerte digna como parte del propio derecho a la vida ante situaciones de enfermedad incurable.}

La primera ocasión en que tuvo oportunidad de pronunciarse al respecto fue en el citado Asunto Pretty c. Reino Unido ${ }^{41}$, que constituiría el pronunciamiento más importante dado por el Tribunal europeo en el que se vierte una verdadera doctrina sobre el derecho a la muerte, seguida por muchos Tribunales constitucionales y vigente hasta la fecha. Es cierto que en los últimos años encontramos algún pronunciamiento más reciente en el que se vislumbra cierta evolución pero que en realidad no ha llegado a consolidarse, manteniéndose de manera reiterada la interpretación dada en la citada sentencia de 2002.

El asunto giraba en torno a la demanda presentada por una ciudadana británica que padecía una enfermedad degenerativa e incurable que inevitablemente le produciría un grave sufrimiento. La demandante denunciaba el rechazo de las autoridades británicas a su petición de auxilio al suicidio con la ayuda de su esposo (ante la imposibilidad de hacerlo por sí misma), para el que solicitaba la exoneración de pena (prevista por las leyes británicas), dada la prohibición de la ayuda al suicidio establecida en el derecho británico.

En la demanda se denunciaba que dicha negativa violaba diversos derechos amparados en el Convenio, fundamentalmente: el derecho a la vida (artículo 2), el derecho a no sufrir tratos inhumanos o degradantes (artículo 3.2), el derecho a la vida privada y familiar (artículo 8), el derecho a la libertad ideológica y de conciencia (artículo 9), y el derecho a la prohibición de discriminación (artículo 14).

A continuación, daremos cuenta de los argumentos alegados por la demandante y la respuesta dada ante aquellos por parte del Tribunal, que como decíamos, constituirán la doctrina seguida respecto al derecho a morir en Europa.

Comenzaremos por el derecho a la vida proclamado en el artículo 2. La demandante pretendía el reconocimiento por parte del Tribunal del derecho a no querer vivir como dimensión negativa del derecho a la vida. De manera textual, la demandante alegaba que: «(...) el artículo 2 protege no la vida misma, sino el

41 Tribunal Europeo de Derechos Humanos, n.2346/o2, 29 de abril de 2002. 
derecho a la vida. Esta cláusula trata de proteger a los individuos contra terceros (el Estado y las autoridades públicas) pero reconoce que corresponde al individuo escoger vivir o no y protegería así el derecho a la autodeterminación de cada uno en relación con las cuestiones de vida y de muerte». A partir de esta premisa, la demandante defendía que: «una persona puede rechazar un tratamiento médico que salve su vida» (ap. 14.4). Defiende que el derecho a la vida proclamado en el Convenio ampara también la dimensión negativa del mismo, esto es, el derecho a morir. Sostiene que, si bien la mayor parte de las personas desean vivir, algunas desean morir, y en consecuencia el Convenio protegería ambos derechos, como materialización de las distintas dimensiones del derecho a la vida: vivir y morir. El derecho a morir no sería entonces la antítesis del derecho a la vida, sino su natural consecuencia, con respecto al que las autoridades públicas tendrían una obligación positiva.

Nótese que en su argumento omitía un elemento esencial para la consideración del derecho de autodeterminación en relación con el derecho a morir. Existe una determinante diferencia entre la opción de morir llevada a cabo por el propio individuo respecto de aquella otra para cuya consecución precisa necesariamente de la colaboración de un tercero. Hasta aquí, incluso si se reconociera la dimensión negativa del derecho a la vida solo sería reconocible en su ejercicio individual y no por parte de terceros, con independencia de que estos fueran particulares o el propio Estado.

La respuesta del Tribunal se circunscribió sobre todo al segundo inciso del artículo 2. La protección impuesta al Estado de proteger la vida, más allá de la abstención de atacarla (contenido obvio), alcanza también la obligación positiva de adoptar las medidas necesarias para protegerla, a través de la legislación penal.

A partir de esta obligación de protección de la vida, llega el momento de determinar si del derecho a la vida proclamado en el artículo 2 del Convenio, es o no extraíble un derecho negativo a la misma, esto es: determinar si existe un derecho a morir.

En palabras del propio Tribunal: «no considera que se pueda interpretar que el «derecho a la vida» garantizado por el artículo 2 conlleva un aspecto negativo» (ap. 39)

Determina de manera tajante, que: «(...) no es posible deducir del artículo 2 del Convenio un derecho a morir, ni de la mano de un tercero ni con la ayuda de 
una autoridad pública» (ap. 40). Con lo que, desestima la pretendida violación del artículo 2 por parte de las autoridades británicas.

En relación con el derecho a no sufrir tratos inhumanos o degradantes (artículo 3.2) y respaldado por su anterior jurisprudencia, la demandada expone los siguientes argumentos: los Estados miembros tienen la obligación de no infligir tratos proscritos y de tomar medidas positivas para evitar que los individuos sean sometidos a dichos tratos ${ }^{42}$; los sufrimientos debidos a la evolución de una enfermedad pueden ser considerados tratos proscritos si el Estado está en condiciones de atenuarlos y no lo hace ${ }^{43}$; negando a la demandante la posibilidad de poner fin a sus sufrimientos, Reino Unido estaría sometiendo a la interesada a un trato proscrito (podría evitarlo si se comprometiera a no iniciar diligencias penales contra su esposo para que pudiera ayudarla a suicidarse); el Convenio de Roma permite al Estado abstenerse de prohibir el suicidio asistido; si las autoridades británicas no pudieran aceptar el compromiso solicitado por la demandante, su legislación penal sería incompatible con el Convenio. Con estos argumentos trataba de justificar que, con su negativa, las autoridades británicas estaban violando su derecho a la integridad física y psíquica.

La protección frente a tratos inhumanos y degradantes realizada por el Tribunal ha girado en torno a la determinación de lo que denomina «plus de gravedad» entendida como el sufrimiento que va más allá de lo soportable. Siguiendo su propia doctrina explica que: «En cuanto a los tipos de «tratos» que dependen del artículo 3 del Convenio, la jurisprudencia del Tribunal habla de «malos tratos» que alcancen un mínimo de gravedad e impliquen lesiones corporales reales o un sufrimiento físico o mental intenso $\mathrm{s}^{44}(\ldots)$. Un trato puede ser calificado de degradante y caer así bajo el peso de la prohibición del artículo 3 si humilla o degrada al individuo, si da testimonio de una falta de respeto a su dignidad humana, incluso la rebaja, o si suscita en el interesado sentimientos de miedo, angustia o inferioridad de forma que se quebrante su resistencia moral o física ${ }^{45}$ »

Ahora bien, en el caso que se plantea concurre la especial situación de enfermedad de la demandante, de manera que el Tribunal determina que: «el sufrimiento

42 Tribunal Europeo de Derechos Humanos, n.25599/94, 23 de septiembre 1998; y Tribunal Europeo de Derechos Humanos, 10 mayo de 2001.

43 Tribunal Europeo de Derechos Humanos, n.30240/96, 2 de mayo de 1997.

44 Tribunal Europeo de Derechos Humanos, n.24724/94, 16 de diciembre de 1999, ap. 71.

45 Tribunal Europeo de Derechos Humanos, n.33394/96, 10 de julio de 2001, ap. 24-30; y Tribunal Europeo de Derechos Humanos, n.44558//98, 24 de julio de 2001, ap. 117. 
debido a una enfermedad que sobreviene de forma natural, tanto si es física como mental, puede depender del artículo 3 si se encuentra o si corre el riesgo de verse intensificada por un trato -tanto si éste se debe a las condiciones de detención, a una expulsión u otras medidas- del que las autoridades pueden ser consideradas responsables ${ }^{46} \gg($ ap. 52$)$

La queja alegada aquí por la demandante suponía una interpretación nueva y ampliada de la noción de «trato», esto es: que el rechazo a aceptar el compromiso de no procesar a su marido si éste le ayudaba a suicidarse, así como la prohibición del suicidio asistido en el derecho penal, deben considerarse un trato inhumano y degradante cuyo responsable sería el Estado, por los sufrimientos que tendrá que soportar si su enfermedad alcanza la fase final.

Ahora bien, aunque el Tribunal debe ser flexible y dinámico al interpretar el Convenio, «instrumento vivo», también debe velar por que toda interpretación que haga del mismo sea de acuerdo con sus objetivos fundamentales y coherente con la protección de los derechos humanos. Así pues, el derecho a la integridad debe ser interpretado en armonía con el derecho a la vida.

Con todo, determina que: «no puede sino sentir simpatía por el temor de la demandante a tener que afrontar una muerte terrible si no se le da la posibilidad de quitarse la vida. Es consciente de que la interesada es incapaz de suicidarse debido a su discapacidad física y que el estado del derecho es tal que su marido corre el riesgo de ser procesado si le presta su ayuda. Sin embargo, el cumplimiento de la obligación positiva invocada en este caso no lleva consigo la supresión o la atenuación del daño producido (...). Exigir del Estado que admita la demanda, es obligar a avalar actos tendentes a interrumpir la vida. Dicha obligación no puede deducirse del artículo 3 del Convenio» (ap. 55)

Y concluye: «el artículo 3 del Convenio no impone al Estado demandado ninguna obligación positiva de aceptar el compromiso de no perseguir judicialmente al marido de la demandante si éste ayudara a su esposa a suicidarse ni de crear un marco legal para cualquier otra forma de suicidio asistido. Por lo tanto, no ha habido violación del artículo 3» (ap. 56)

El siguiente argumento planteado fue la violación del derecho a la vida privada y familiar reconocida en el artículo 8. Recordemos la complejidad que supone este precepto, por cuanto la protección dada en su primer inciso puede ser empañada

46 Tribunal Europeo de Derechos Humanos, n.30240/96, 2 de mayo de 1997; y Tribunal Europeo de Derechos Humanos, n.27229/95, 3 de abril de 2001. 
por lo previsto en el segundo, en el que se reconocen ciertos parámetros bajo los cuales podría justificarse la proporcionalidad de ciertas restricciones sobre el pretendido derecho (recordemos a estos efectos lo expuesto en relación con el aborto).

Así, haremos una diferenciación entre ambos epígrafes a la hora de analizar los argumentos y los fundamentos jurídicos extraídos de la sentencia que nos ocupa.

En primer lugar, la demandante defiende que el derecho a la vida privada confiere a los individuos un derecho a la autodeterminación, como premisa para su pleno desarrollo, que englobaría el derecho a escoger cuándo y cómo morir, de forma que se evite el sufrimiento y la indignidad. Prohibir esta libertad de decisión, supondría una injerencia en su derecho a la vida privada. Correspondería al Estado justificar tal restricción, a partir de los criterios de legalidad, de necesidad y de proporcionalidad, que derivan del Convenio.

A lo anterior, añadía que se tuviera en cuenta su estado en plenas facultades mentales, la horrible perspectiva de lo que le vendría incluyendo la inminencia de su fatal desenlace, el hecho de que se suicidaría si tuviera la posibilidad de hacerlo por ella misma, y junto a lo anterior, que se tuviera en cuenta que su suicidio asistido no causaría daño a nadie más (ni siquiera sería un daño para ella)

Al Tribunal corresponde determinar si la negativa de las autoridades británicas a aceptar el compromiso solicitado podría considerarse o no una injerencia desproporcionada.

Como punto de partida considera que, en efecto, una persona puede reivindicar el derecho a ejercer su elección de morir rechazando un tratamiento que pudiera prolongar su vida. Y lo contrario sería un ataque a su integridad física y a su vida privada. No puede imponerse un tratamiento médico en contra de la voluntad del individuo en plena capacidad de obrar (adulto y mentalmente capaz)

Pero el debate no está en los cuidados médicos. La demandante en cuestión padece una enfermedad incurable degenerativa que conlleva el inevitable deterioro gradual de su estado y un incremento de su sufrimiento físico y mental. $\mathrm{Su}$ pretensión no es otra que acabar con su sufrimiento poniendo fin a su vida: elegir cómo se quiere vivir el final de su existencia, es una decisión que forma parte de su vida privada, ligada a su libertad y a su dignidad.

En su respuesta, el Tribunal reflexiona acerca de la noción «calidad de vida» que, pese a la innegable protección del derecho a la vida, adquiere pleno significado desde el derecho a la vida privada protegido en el Convenio. Esta conexión 
supone que si se establecen restricciones o prohibiciones que suponen un deterioro de la calidad de vida de las personas, se viola su vida privada. En palabras del Tribunal: «la demandante en este caso se ve impedida por la Ley para ejercer su elección de evitar lo que, en su opinión, será un final indigno y penoso. El Tribunal no puede excluir que esto representa una vulneración al derecho de la interesada al respeto de su vida privada, en el sentido del artículo 8.1 del Convenio (...)» (ap. 67).

Sin embargo, pese al reconocimiento de la injerencia que supuso la negativa de las autoridades británicas sobre su derecho a la vida privada y el consecuente daño sobre su dignidad y su libertad, el Tribunal estimó que no existió vulneración de su derecho porque concurrían los parámetros previstos en el Convenio ${ }^{47}$ para justificar dicha injerencia: "para conciliarse con el apartado 2 del artículo 8, una injerencia en el ejercicio de un derecho garantizado por éste debe estar «prevista por la Ley», inspirada por uno o más fines legítimos según dicho apartado y ser «necesaria en una sociedad democrática» para alcanzar dicho o dichos fines ${ }^{48}{ }^{8}$ » (ap. 68).

A continuación, entra en un elemento fundamental para enjuiciar la proporcionalidad de la injerencia, la requerida necesidad. Según la jurisprudencia del Tribunal: «la noción de necesidad implica que la injerencia corresponda a una necesidad social imperiosa $y$, en concreto, que sea proporcional al fin legítimo perseguido. Para determinar si una injerencia es «necesaria en una sociedad democrática», hay que tener en cuenta el margen de apreciación de que disponen las autoridades nacionales, cuya decisión sigue sometida al control del Tribunal, competente para verificar su conformidad con las exigencias del Convenio. Dicho margen de apreciación varía según la naturaleza de las cuestiones y la importancia de los intereses en juego» (ap. 70)

Con lo anterior, concluye que la injerencia enjuiciada puede considerarse justificada y «necesaria en una sociedad democrática» para la protección de los derechos. Por lo tanto, tampoco hubo violación del artículo 8.

47 Artículo 8.2: «No podrá haber injerencia de la autoridad pública en el ejercicio de este derecho, sino en tanto en cuanto esta injerencia esté prevista por la Ley y constituya una medida que, en una sociedad democrática, sea necesaria para la seguridad nacional, la seguridad pública, el bienestar económico del país, la defensa del orden y la prevención del delito, la protección de la salud o de la moral, o la protección de los derechos y las libertades de los demás».

48 Tribunal Europeo de Derechos humanos, n.7525/76, 22 de octubre de 1981, ap. 43. 
Otro argumento alegado por la demandante era la violación de la libertad ideológica y religiosa del artículo $9^{49}$ del Convenio, si bien el Tribunal apenas entró en ello. Frente a la pretendida injerencia en su convicción respecto al suicidio asistido, el Tribunal responde que no todas las opiniones o convicciones entran en el campo de aplicación del artículo 9.1: «las quejas de la interesada no hacen referencia a una forma de manifestación de una religión o de una convicción por medio del culto, la enseñanza, la práctica o la observancia de los ritos»

Por último, la demandante alegaba la vulneración de la prohibición de discriminación prevista en el artículo $14^{50}$, sosteniendo que: «(...) el artículo 2.1 de la Ley de 1961 es discriminatorio para con aquellos que, como ella, son incapaces, debido a su invalidez, de poner fin a sus días sin ayuda» ${ }^{51}$ (ap. 14.32)

El Tribunal también descartó este argumento, recordando que la diferencia de trato entre personas en situaciones análogas o comparables es discriminatoria si no se basa en una justificación objetiva y razonable, circunstancia que no apreció en el caso en cuestión; en su opinión: «(...) existe una justificación objetiva y razonable para la no distinción jurídica entre las personas físicamente capaces de suicidarse y las que no lo son» (ap.89).

\subsubsection{Colaboración del Estado con el auxilio al suicidio en países en los que es legal}

49 Artículo 9: «Toda persona tiene derecho a la libertad del pensamiento, de conciencia y de religión; este derecho implica la libertad de cambiar de religión o de convicciones, así como la libertad de manifestar su religión o sus convicciones individual o colectivamente, en público o en privado, por medio del culto, la enseñanza, las prácticas y la observación de los ritos; 2.La libertad de manifestar su religión o sus convicciones no pueden ser objeto de más restricciones que las que, previstas por la Ley, constituyen medidas necesarias, en una sociedad democrática, para la seguridad pública, la protección del orden, de la salud o de la moral públicas, o la protección de los derechos o las libertades de los demás».

50 Artículo 14: «El goce de los derechos y libertades reconocidos en el presente Convenio ha de ser asegurado sin distinción alguna, especialmente por razones de sexo, raza, color, lengua, religión, opiniones políticas $\mathrm{u}$ otras, origen nacional o social, pertenencia a una minoría nacional, fortuna, nacimiento o cualquier otra situación».

51 Tribunal Europeo de Derechos Humanos, n.34369/97, 6 de abril de 20oo: «El Tribunal, hasta el momento, ha dictaminado la violación del derecho garantizado por el artículo 14 de no sufrir discriminación en el disfrute de los derechos reconocidos por el Convenio cuando los Estados tratan de manera diferente sin justificación objetiva y razonable a las personas que se encuentran en situaciones análogas. Sin embargo, considera que no es la única faceta de la prohibición de cualquier discriminación enunciada por el artículo 14. El derecho a disfrutar de los derechos garantizados por el Convenio sin ser sometido a discriminación es igualmente transgredido cuando, sin justificación objetiva y razonable, los Estados no tratan de manera diferente a personas en situaciones sensiblemente diferentes» (ap. 44). 
Dejando a un lado el que ha sido el primer y más importante pronunciamiento del Tribunal sobre el derecho a morir, entremos en el Asunto Haas contra Suiza ${ }^{52}$

El asunto presenta el caso de un ciudadano suizo que denuncia la violación de su vida privada y familiar protegida, por cuanto el Estado no colaboró con su deseo de poner fin a su vida. El demandante, presentaba un grave trastorno afectivo bipolar que le impedía vivir dignamente y por el que deseaba acabar con su vida. La legislación suiza es una de las que permiten el auxilio al suicidio, pero establece ciertos requisitos de control como es la necesidad de que sea un especialista el que recete la sustancia letal, para asegurar que la decisión de morir sea voluntaria y meditada, y no fruto de una decisión apresurada o de abuso por parte de terceros.

En el caso que se presenta, el demandante no tuvo acceso a la sustancia letal al carecer de prescripción médica a tal efecto, denunciando al Estado por la exigencia legal de dicha prescripción, al considerar que interfería en su decisión personal amparada en el derecho a la vida privada: «(...) la injerencia en el ejercicio de su derecho al respeto de la vida privada, protegido por el artículo 8.1, no encuentra justificación ni en la protección de su propia vida ni en los intereses relacionados con la salud o la seguridad públicas. La imposibilidad de encontrar un psiquiatra dispuesto a emitir un informe convirtió en ilusorio su derecho al respeto de su vida privada» (ap. 37).

En su respuesta, el Tribunal comenzó recordando que a la luz de su jurisprudencia: «(...) el derecho de una persona a decidir de qué forma y en qué momento debe terminar su vida, siempre y cuando esté en condiciones de forjar libremente su voluntad y actuar en consecuencia, es uno de los aspectos del derecho al respeto de la vida privada en el sentido del artículo 8 del Convenio» (ap. 51) El margen de apreciación no supone solo la libertad de decisión acerca de la legalización de estas prácticas, sino también la determinación de las obligaciones o requisitos acerca de las mismas ${ }^{53}$.

Ahora bien, el Tribunal hizo hincapié en la marcada diferencia que presentaba este caso en relación con el asunto Pretty: «(...) a diferencia del asunto Pretty, el demandante alega no solamente que su vida es difícil y dolorosa, sino tam-

52 Tribunal Europeo de Derechos Humanos, n.31322/97, 20 de enero de 2011.

53 CaÑamares (2016): "Al mismo tiempo, aquellos Estados que han legalizado estas prácticas disfrutan también de un amplio margen de apreciación a la hora de determinar cuáles son sus obligaciones positivas, ya que tampoco existe un consenso en relación con cuáles son estas en el marco del art. 8 del Convenio» (p.343). 
bién que, si no obtiene la sustancia en litigio, el acto suicida resultaría indigno. Además, y siempre a diferencia del asunto Pretty, al demandante no se le puede considerar realmente una persona inválida, en la medida en que no se encuentra en fase terminal de una enfermedad degenerativa incurable que le impediría suicidarse (...)» (ap. 52)

Entrando en la ponderación de los intereses concurrentes, el Tribunal reconoció la voluntad del demandante de suicidarse de forma segura, digna y sin dolor ni sufrimientos superfluos, atendiendo especialmente al elevado número de intentos de suicidio que fracasan y que a menudo tienen graves consecuencias para las víctimas y sus familiares. Pero, junto a lo anterior, consideró también que las condiciones previstas por la ley son razonables porque obedecen al legítimo objetivo de proteger a cualquier persona de una decisión precipitada y evitar abusos, máxime tratándose de una regulación permisiva del suicidio asistido.

Finalmente, el Tribunal recuerda que sobre el asunto de la muerte digna no existe un consenso en los Estados parte del Consejo de Europa, por lo que los Estados disponen de un amplio margen de apreciación, concluyendo que no hubo violación al Convenio por parte del Estado suizo ${ }^{54}$.

\subsubsection{Auxilio al suicidio por vejez en ausencia de enfermedad incurable}

El siguiente caso propuesto es el Asunto Alda Gross c. Suiza ${ }^{55}$ (recurrida en Gran Sala, e inadmitida con fecha de 30 de septiembre de 2014). Se trata de la demanda interpuesta por una persona mayor que deseaba ponerle fin a su vida sin que concurriese ninguna enfermedad incurable o insoportable.

La demandante denunciaba la intromisión en su vida privada por parte de las autoridades suizas al no facilitarle la sustancia letal para alcanzar su propósito (para cuyo acceso, como se apuntó en caso anterior, la ley exigía la correspondiente prescripción médica). La queja se basaba en la falta de precisión de la legislación suiza respecto a las condiciones específicas en las que se permitía la asistencia al suicidio, entre las que no se encontraba la vejez.

54 «Habida cuenta de lo que antecede, y atendiendo al margen de apreciación de que disponen en este ámbito las autoridades internas, el Tribunal estima que suponiendo incluso que los Estados tuvieran la obligación positiva de adoptar medidas que posibiliten el suicidio con dignidad, las autoridades suizas no violaron esta obligación en el presente caso». Concluyendo que: «De ello se infiere que no ha habido violación del artículo 8 del Convenio» (ap. 61).

55 Tribunal Europeo de Derechos Humanos, n.67810/10, 14 de mayo de 2013. 
Se trata de un caso particular. En primera instancia, en su Sentencia de Sala, el Tribunal estimó su pretensión declarando una efectiva injerencia sobre la vida privada de la demandante dada la falta de precisión de la legislación denunciada: «(...) corresponde a las autoridades suizas establecer unas líneas normativas lo suficientemente claras capaces de abarcar cómo y bajo qué condiciones individuales, como las planteadas en la situación de la demandante (...), se debería conceder la capacidad de adquirir una dosis letal de medicación permitiéndole terminar con su vida».

Concluyendo así que: «la ausencia de un marco normativo lo suficientemente amplio y claro ha supuesto una violación del derecho a la vida privada de la denunciante, recogido en el artículo 8 del Convenio» (ap. 69), una falta de claridad que algunos autores califican como disuasorias ${ }^{56}$.

Pero, tras la inadmisión del recurso presentado a Gran Sala por parte del gobierno suizo, los efectos de la primera sentencia perdieron su validez jurídica, al estimar el Tribunal la concurrencia de engaño por parte de la demandada, que deliberadamente habría ocultado incluso a su propio abogado la noticia de su muerte durante el desarrollo del proceso ante el Tribunal de Estrasburgo para evitar que éste pudiera declarar finalizado el procedimiento.

Con todo, las extravagantes circunstancias que se dieron en dicho procedimiento dejan sin resolver la cuestión central del mismo. En la actualidad, ya se está planteando en algún Estado (Holanda) el peligroso reconocimiento legal del suicidio asistido por vejez, entendiendo que forma parte de la vida privada la decisión de poner fin a su vida, con independencia de las circunstancias concurrentes (sin exigir las condiciones de sufrimiento, o enfermedad grave e incurable).

\subsubsection{Suspensión de la prolongación artificial de la vida por decisión de las autoridades}

Otro de las cuestiones relacionadas con el derecho a la vida, en su proceso final, es la de la suspensión de la prolongación artificial y sin esperanza de recuperación,

56 Climent (2018):» Esta ausencia de directrices legales claras es probable que tenga un efecto paralizador en los médicos que, de otra manera, estarían dispuestos a proporcionar a alguien como la demandante, la receta médica solicitada»; «Esta ausencia normativa, y las angustiosas consecuencias que tuvo en la demandante, es lo que sirve de fundamento al TEDH para considerar que, efectivamente, se vulneró el derecho de a demandante al respeto a su vida privada del artículo 8 CEDH» (p.137). 
por parte de las autoridades. Este es el supuesto planteado en el Asunto Vincent Lambert c. Francia ${ }^{57}$.

El caso tiene su origen en la legislación francesa vigente, que autoriza el cese de los tratamientos que mantienen de manera artificial la vida, en el caso de enfermedad irreversible, en contra de la voluntad del individuo, prohibiendo lo que se ha denominado el «encarnizamiento» terapéutico. En aplicación de esta ley, se adoptó la decisión médica de suspender el tratamiento que mantenía con vida al Sr. Vicent Lambert, de 38 años, tetrapléjico y en estado vegetativo desde hacía siete, tras sufrir un accidente de moto.

En contra de esta decisión, los padres del Sr. Lambert la denunciaron ante el Consejo de Estado, que en sentencia de 24 de junio de 2014 rechazó sus pretensiones, e inmediatamente la pusieron en conocimiento del Tribunal de Estrasburgo que suspendió la desconexión hasta dictar sentencia (en 5 de junio de 2015).

El problema de fondo está en la ausencia de voluntad anticipada del paciente, que ponía en entredicho la legitimidad de la decisión adoptada por el hospital. Sin embargo, la decisión médica fue adoptada por el jefe de cuidados paliativos del hospital de Reims tras consultar a varios médicos especialistas, a la esposa y a varios hermanos del paciente.

Meses más tarde, el Tribunal resolvió el asunto declarando que no hubo violación del derecho a la vida protegido en el artículo 2 del Convenio, por parte de las autoridades francesas, y que éstas respetaron la ley.

Nótese que la sentencia europea se limita a examinar el respeto por parte del Estado francés de sus obligaciones positivas derivadas del artículo 2 del Convenio, concretadas en su legislación. Pero no entra en consideraciones de fondo respecto a la suspensión de determinados tratamientos médicos que mantienen artificialmente la vida, recurriendo una vez más al margen de apreciación de los Estados (en este caso, Francia) ante la ausencia de consenso europeo al respecto.

\subsubsection{Asistencia al suicidio de un menor.}

Finalmente, planteamos el que probablemente es el supuesto más complejo y controvertido de los relacionados con el derecho de decisión sobre proceso final de la vida, la eutanasia en menores. No es exactamente un supuesto de eutanasia, sino de suspensión de tratamientos médicos que mantienen artificialmente con

57 Tribunal Europeo de Derechos Humanos, n.46043/14, 5 de junio de 2015. 
vida a pacientes con enfermedades irreversibles e incurables, pero a diferencia del planteado con anterioridad, en este caso se plantea respecto de un menor de edad.

Este es el mediático supuesto planteado en el reciente Asunto Gard c. Reino $U_{n i d o}{ }^{58}$, sobre la suspensión del mantenimiento artificial de la vida de un bebé, afectado por una enfermedad genética rara.

Lo controvertido del caso radica en la oposición de los padres del menor frente a la decisión médica de poner fin a la prolongación de la vida artificial del niño y de suspensión de cuidados paliativos. Decisión especialmente compleja y controvertida tratándose de un menor que cuenta con férreos defensores pero también con fuertes detractores (algunos lo han llegado a calificar de «encarnizamiento terapéutico $\left.{ }^{59}\right)$. Esta decisión fue autorizada por la Suprema Corte de Reino Unido, y denunciada por los padres ante el Tribunal Europeo.

El Tribunal de Estrasburgo, decidió inadmitir la demanda, reafirmándose en la decisión de los jueces británicos de suspender el tratamiento médico del menor en EEUU. Una vez más, ante un tema complejo, con fuertes connotaciones morales y éticas, y sobre la que no existe un amplio consenso, cerró los ojos y dejó la decisión en manos del Estado.

\section{Reflexiones a modo de conclusión}

El derecho a la vida es un derecho complejo, ambiguo e indeterminado, en lo que se refiere a la dificultad de establecer la frontera entre la vida y el derecho a la vida, fundamentalmente en cuanto a la determinación de su comienzo y su final.

Como todos, el derecho a la vida no es absoluto, sino que está sujeto a posibles restricciones. Pero en todo caso, restricciones que tienen que cumplir con los criterios de razonabilidad y proporcionalidad. Hasta aquí, no habría conflicto.

Son los Estados soberanos quienes dibujan los contenidos del derecho a la vida. Aquí es donde se presenta el conflicto, a la hora de determinar cuándo la regulación nacional establece restricciones sobre el derecho a la vida (si lo hace) conformes a ese criterio de proporcionalidad y razonabilidad, y cuándo se trata de límites desproporcionados que agreden otros derechos en juego.

58 Tribunal Europeo de Derechos Humanos, n.39793/17, 28 de junio de 2017.

59 MARÍN-CASTÁN (2018): «Ciertamente, mantener a cualquier precio la vida de un paciente cuando dichos facultativos coinciden en apreciar que se trata de un proceso irreversible nos puede llevar a incurrir en el considerado encarnizamiento terapéutico o distanasia con la utilización de medios desproporcionados que pueden contribuir a incrementar el sufrimiento que ya de por sí comporta la enfermedad». 
En el caso del aborto, la libertad de las mujeres, su integridad, vida privada y familiar, o sus derechos sexuales y reproductivos; en el caso de la eutanasia, la vida privada y familiar, o la integridad física y psíquica.

Frente a la actuación de los Estados, es el Tribunal de Estrasburgo, garante de los derechos humanos, a quien le correspondería dar un contenido más preciso al derecho a la vida. Sin embargo, hasta la fecha no lo ha hecho, amparado en el margen de apreciación nacional. Se ha limitado a dar ciertos parámetros que deben concurrir para legitimar las eventuales restricciones impuestas por los distintos ordenamientos jurídicos, que servirían de límite a la libertad de los Estados soberanos. Estas pautas, garantía de los derechos, deberían ser infranqueables.

Pero introduce un peligroso elemento: la moral y la tradición, como refuerzo a la autoridad nacional, que flexibiliza desproporcionadamente los límites del margen de apreciación nacional.

Sorprendentemente y en contra de lo que es su jurisprudencia, en términos generales, en el caso del derecho a la vida, el Tribunal ha priorizado los valores morales y religiosos por encima del consenso europeo. Una actitud que sin duda resulta cada vez más incoherente y contraria al espíritu del Convenio de Derechos Fundamentales de la Unión Europea.

En mi opinión, es un retroceso en el reconocimiento de la libertad y la vida privada de las personas, priorizando la protección del no nacido o, en su caso, imponiendo la obligación de vivir, sobre los derechos de aquellas, y justificando la proporcionalidad de tal intromisión, en base a los valores morales profundos.

La conclusión extraída del recorrido jurisprudencial del Tribunal Europeo de Derechos Humanos, y a pesar de la vaguedad de sus argumentos y de la falta de contundencia en sus decisiones, es que el aborto y la decisión de morir no son derechos fundamentales extraídos del Convenio, ni como derechos ubicados en el artículo 3 (derecho a la vida) ni como manifestación del artículo 8 (vida privada), a pesar del inseparable vínculo con ellos, admitido por el Tribunal.

La tendencia es la legalidad del aborto, regulado normalmente en leyes de plazos que no de supuestos (y lo mismo parece ir advirtiéndose en el caso de la eutanasia).

Pero el Tribunal europeo no puede permanecer ajeno a la realidad por mucho más tiempo. En sus últimas decisiones deja entrever lo que se aventura como una probable nueva tendencia pro-libertad que vendría a reconocer el derecho a la vida privada de las mujeres con respecto a su decisión de ser madres, y por exten- 
sión el derecho de todos para decidir acerca de nuestra vida, incluido su proceso final.

El argumento de los valores morales profundos como motivo de la restricción de derechos humanos ya no tiene mucho más recorrido o, al menos, no debería tenerlo.

\section{Bibliografía citada}

Alegre martinez, Miguel Ángel (2002): «Apuntes sobre el derecho a la vida en España. Constitución, jurisprudencia y realidad», en Revista de Derecho Politico (núm. 53, 2002), pp. 337-360

Alegre martinez, Miguel Ángel (2012): «El derecho a la vida como derecho a nacer», en Estudios de Deusto (núm. 1, vol.6o/1. 2002), pp. 375-382

BASCUÑán, Antonio (2016): «Desarrollos recientes en la jurisprudencia sobre el derecho a morir», en Revista Médica Chile (núm. 144), pp. 483-487

Benavides Casals, M.A. (2009): «El consenso y el margen de apreciación en la protección de los derechos humanos», en Ius et Praxis (vol.15, núm.1. 2009), pp. 295-310

Cañamares Arribas, Santiago (2016): «La reciente jurisprudencia del Tribunal de Estrasburgo y del Tribunal Supremo en Canadá en relación con el derecho a la muerte digna», en Revista Española de Derecho Constitucional (núm.1o8, septiembre-diciembre 2016), pp. 337-356.

Clérigo, Laura (2020): «El argumento de la falta de consenso regional en derechos humanos. Divergencia entre el TEDH y la Corte IDH», en Revista Derecho del Estado (núm.46, mayo-agosto 2020), pp. 57-83

Climent Gallart, Jorge Antonio (2018): «La jurisprudencia del TEDH sobre el derecho a disponer de la propia vida», en Actualidad Jurídica Iberoamericana (núm. 8, feb. 2018), pp.124-137

FreiXes SANJUÁN, Teresa (1997): «Las principales construcciones jurisprudenciales del TEDH», en Gómez SÁnchez, Yolanda (coord.) Los derechos en Europa (UNED, Madrid)

GARCÍA RocA, Javier (2007): «La muy discrecional doctrina del margen de apreciación nacional según el Tribunal Europeo de Derechos Humanos: soberanía e integración», en Teoría y Realidad Constitucional (núm.20. 2007), pp. 117-143 
Gómez Montoro, Ángel José (2018): «El Estatuto Constitucional del no nacido: evolución y situación actual en España», en Revista de Derecho Político (núm. 102. 2018), pp. $47-78$

Gónzalez Prado, Patricia (2020): «Jurisprudencia comparada sobre aborto: cuando los feminismos impregnan el derecho», en Cuadernos electrónicos de filosofía del derecho (núm. 42. 2020), pp.135-157

Gónzalez Vélez, Ana Cristina (2018): «Objeción de conciencia, bioética y derechos humanos: una perspectiva desde Colombia», en Revista de bioética y derecho: publicación del Máster en bioética y derecho (núm. 42. 2018), pp. 105-126 Levín, Silvia (2018): «¿Salud sexual y salud reproductiva sin libertad?: el conflicto por el aborto en Argentina», en Salud colectiva (vol.14, núm. 3. 2018), pp. 377-389,

López Alfonsín, M.A. (2017): «La doctrina del margen de apreciación nacional. Su recepción en el Sistema Europeo de Derechos Humanos, en el Sistema Interamericano de Derechos Humanos y en Argentina, en relación con los derechos económicos, sociales y culturales», en Lex (núm.19, año XV. 2017), pp. $51-76$

MARÍn-CASTÁn, Maria Luisa (2018): «La polémica decisión del Tribunal Europeo de Derechos Humanos sobre el caso Gard y otros contra el Reino Unido» en Revista de Bioética y Derecho (núm. 43, 2018)

Martí, Silvia, Sánchez, Javier y Recoder, Tatiana. (2007): «Comentarios jurisprudenciales: los derechos en el TEDH, un análisis», en Universitas. Revista de Filosofía, Derecho y Política (núm. 5, enero), pp. 91-156

Martinez Guillem, Ramón (2002): «Comentario sobre la Sentencia del Tribunal Europeo de Derechos Humanos de 4 de mayo de 2001 (Kelly y otros contra el Reino Unido)», en Anuario de Derecho Internacional (Vol. XVIII), pp. 255-278

Manzano SousA, Manuel (2003): «El derecho a la vida. La fuerza armada en una situación límite: la amenaza terrorista en Gibraltar (Comentarios a la STEDH de 27 de septiembre de 1995, Caso McCann y otros contra el Reino Unido)», en Seguridad ciudadana y globalización, pp. 169-140

Mena Parras, Francisco Javier (2012): «La sentencia A, B y C contra Irlanda: ¿Un punto de inflexión en la jurisprudencia de la Corte Europea de Derechos Humanos en materia de consenso y margen de apreciación nacional?», en Anuario de Derechos Humanos (U. Chile), pp.115-124. www.anuariocdh.uchile.cl 
Molero Martín-Salas, M. Pilar (2014): El derecho de disponer de la propia vida desde la perspectiva constitucional (Centro de Estudios Políticos y Constitucionales, Madrid)

Monereo Pérez, J.L. (2019): «La garantía del derecho a la salud y la asistencia sanitaria en la normativa internacional general y comunitaria», en Derecho de las relaciones laborales (núm.3. 2019), pp. 255-296.

Murillo de la Cueva, E. Lucas (2019): «Derechos Humanos y atención sanitaria ante el Tribunal Europeo de Derechos Humanos», en Extraordinario XXVIII Congreso 2019, Ponencias (vol.29. 2019), pp. 6-30

Pascual Vives, F.J. (2013): «El margen de apreciación nacional en los tribunales regionales de derechos humanos: una aproximación consensualista», en Anuario Español de Derecho Internacional (núm.19. 2013), pp. 217-262

Rey MARTínez, Fernando (2009): «La protección jurídica de la vida ante el Tribunal de Estrasburgo: un derecho en transformación y expansión, en Estudios Constitucionales (año 7, núm.1), pp.331-360

Rey Martínez, Fernando (2011): «¿Es el aborto un derecho en Europa?, comentario de la sentencia «A, B y C v. Irlanda» del Tribunal Europeo de Derechos Humanos», en Estudios Constitucionales (año 9, núm. 2), pp. 743-752

Rey Martínez, Fernando (2012): «¿Qué significa en el ordenamiento español el derecho a 'vivir con dignidad el proceso de la muerte'?», en Revista de la Facultad de Derecho. PUCP (núm. 69), pp. 133-149

Rey Martínez, Fernando (2018): «Protección de la salud, atención primaria y derechos fundamentales», en Teoría y Realidad Constitucional (núm.41. 2018), pp. 291-295

Ropero Carrasco, Julia (2003): «La insuficiencia del sistema de indicaciones en el delito de aborto», en Anuario de Derecho Penal y Ciencias Penales (vol.LVI. 2003)

Ropero Carrasco, Julia (2016): «Delitos de aborto», en Molina Fernández, F. (coord.) Memento Práctico (Ed.Francis Lefevbre Penal, Madrid), pp. 47-78

Ruiz Miguel, Alfonso (1993): «Autonomía individual y derecho a la propia vida (Un análisis filosófico-jurídico)», en Revista del Centro de Estudios y Constitucionales (núm. 14, enero-abril), pp. 135-165

Ruiz Miguel, Alfonso (2010): "Autonomía individual y derecho a la propia muerte», en Revista Española de Derecho Constitucional (núm. 89, mayo-agosto. 2010), pp. 11-43 
Salinero Alonso, Carmen (2018): «El aborto no punible en el ordenamiento jurídico español: la -casi eterna- respuesta a una incertidumbre», en Revista Electrónica de Ciencia Penal y Criminología (núm. 20-31. 2018), pp. 1-34

Sánchez Molina, P. (2016): «Margen de apreciación nacional (en los sistemas de protección internacional de los derechos humanos)», en Eunomía. Revista en cultura de la legalidad (núm.9, octubre 2015-marzo 2016. 2016), pp. 224-231 Sanciñena Asurmendi, Camino (2010): «Autonomía y derecho a la vida», en Derecho Privado y Constitución (núm. 24, enero-diciembre), pp. 369-397

Sarmiento, Daniel, Mieres Mieres, Luis Javier y Presno Linera, Miguel Ángel (2007): Las sentencias básicas del Tribunal Europeo de Derechos Humanos (Civitas, 2007)

Valenzuela Oyaneder, Celia y Villavicencio Miranda, Luis (2015): «La constitucionalización de los derechos sexuales y reproductivos. Hacia una igual ciudadanía para las mujeres», en Revista Ius et Praxis (año 21, núm. 1. 2015), pp. 271-314

\section{Jurisprudencia citada}

X. c. Reino Unido (1980): Comisión Europea de Derechos Humanos 13 de mayo de 1980

Open Door c. Irlanda (1992): Tribunal Europeo de Derechos Humanos 29 de octubre de 1992

Dudgeon c. Reino Unido (1981): Tribunal Europeo de Derechos Humanos 22 de octubre de 1981

Rasmussen c. Dinamarca (1984): Tribunal Europeo de Derechos Humanos 28 de noviembre de 1984

McCann y Otros c. Reino Unido (1995): Tribunal Europeo de Derechos Humanos 27 de septiembre de 1995

D. c. Reino Unido (1997): Tribunal Europeo de Derechos Humanos 2 de mayo de 1997

A. c. Reino Unido (1998): Tribunal Europeo de Derechos Humanos 23 de septiembre de 1998

V. c. Reino Unido (1999): Tribunal Europeo de Derechos Humanos 16 de diciembre de 1999

Thlimmenos c. Grecia (2000): Tribunal Europeo de Derechos Humanos 6 de abril de 2000 
A. D. T. c. Reino Unido (200o): Tribunal Europeo de Derechos Humanos 31 de julio de 2000

Camp y Bourimi c. Países Bajos (200o): Tribunal Europeo de Derechos Humanos 3 de octubre de 2000

Keenan c. Reino Unido (2001): Tribunal Europeo de Derechos Humanos 3 de abril de 2001

Z. y Otros c. Reino Unido (2001): Tribunal Europeo de Derechos Humanos 10 de mayo de 2001

Valasinas c. Lituania (2001): Tribunal Europeo de Derechos Humanos 24 de julio de 2001

Price c. Reino Unido (2001): Tribunal Europeo de Derechos Humanos 10 de julio de 2001

Pretty c. Reino Unido (2002): Tribunal Europeo de Derechos Humanos 29 de abril de 2002

C. Goodwin c. Reino Unido (2002): Tribunal Europeo de Derechos Humanos 11 de julio de 2002

Vo. c. Francia (2004): Tribunal Europeo de Derechos Humanos 8 de julio de 2004

Leyla Sahin c. Turquía (2005): Tribunal Europeo de Derechos Humanos 10 de noviembre de 2005

Steel y Morris c. Reino Unido (2005): Tribunal Europeo de Derechos Humanos 10 de febrero de 2005

Tysiac c. Polonia (2007): Tribunal Europeo de Derechos Humanos 20 de marzo de 2007

Schalk y Kopf c. Austria (2010): Tribunal Europeo de Derechos Humanos 24 de junio de 2010

A B y C c. Irlanda (2010): Tribunal Europeo de Derechos Humanos 16 de diciembre de 2010

Haas c. Suiza (2011): Tribunal Europeo de Derechos Humanos 20 de enero de 2011

R.R. c. Polonia (2011): Tribunal Europeo de Derechos Humanos 26 de mayo de 2011

S.H. y Otros c. Austria (2011): Tribunal Europeo de Derechos Humanos 3 de noviembre de 2011

P y S c. Polonia (2012): Tribunal Europeo de Derechos Humanos 30 de octubre de 2012 
Alda Gross c. Suiza (2013): Tribunal Europeo de Derechos Humanos 14 de mayo 2013

Vincent Lambert c. Francia (2015): Tribunal Europeo de Derechos Humanos 5 de junio 2015,

Gard c. Reino Unido (2017): Tribunal Europeo de Derechos Humanos 28 de junio 2017

Grimmark y Steen c. Suecia (2020): Tribunal Europeo de Derechos Humanos 12 de marzo 2020

STC 53/1985: Tribunal Constitucional español 11 de abril de 1985 